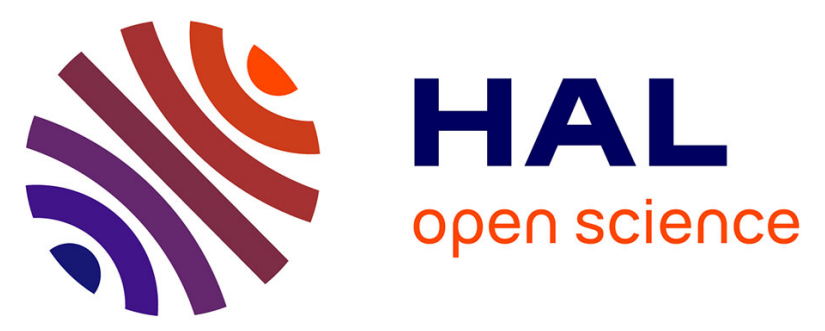

\title{
Hybrid larch heterosis: for which traits and under which genetic control?
}

Alexandre Marchal, Facundo Munoz, Frédéric Millier, Leopoldo Sanchez, Luc E. Pâques

\section{- To cite this version:}

Alexandre Marchal, Facundo Munoz, Frédéric Millier, Leopoldo Sanchez, Luc E. Pâques. Hybrid larch heterosis: for which traits and under which genetic control?. Tree Genetics and Genomes, 2017, 13 (5), 17 p. 10.1007/s11295-017-1177-1 . hal-01604189

\section{HAL Id: hal-01604189 \\ https://hal.science/hal-01604189}

Submitted on 26 May 2020

HAL is a multi-disciplinary open access archive for the deposit and dissemination of scientific research documents, whether they are published or not. The documents may come from teaching and research institutions in France or abroad, or from public or private research centers.
L'archive ouverte pluridisciplinaire HAL, est destinée au dépôt et à la diffusion de documents scientifiques de niveau recherche, publiés ou non, émanant des établissements d'enseignement et de recherche français ou étrangers, des laboratoires publics ou privés.

\section{다(1)(2)}

Distributed under a Creative Commons Attribution - ShareAlikel 4.0 International 
Version définitive du manuscrit publié dans / Final version of the manuscript published in : Tree Genetics \& Genomes, october 2017, https://doi.org/10.1007/s11295-017-1177-1

\title{
Hybrid larch heterosis: for which traits and under which genetic control?*
}

\author{
Alexandre Marchal ${ }^{1}$, Facundo Muñoz ${ }^{1}$, Frédéric Millier ${ }^{1}$, Leopoldo Sánchez ${ }^{1}$, and Luc E. \\ Pâques $^{\dagger 1}$ \\ ${ }^{1}$ INRA - Institut National de la Recherche Agronomique, UR 0588 AGPF - Unité de recherche Amélioration, \\ Génétique et Physiologie Forestières. Centre de recherche Val de Loire, Orléans, France.
}

August 29, 2017

\begin{abstract}
Despite the interest foresters have for interspecific hybrid trees, still little is known about their quantitative genetics. This is especially true for the hybrid (HL) between Larix decidua (EL) and L. kaempferi (JL). Long-term, well-designed, multi-site experiments are necessary to estimate the parameters required for HL breeding programs. This paper presents the results from a diallel mating trial between $9 \mathrm{EL}$ and $9 \mathrm{JL}$, set up in 3 contrasted sites. Growth traits (height, circumference), quality traits (wood density, stem form, heartwood proportion), and bud flush were measured from plantation to up to 18 years after plantation. Wood density and heartwood proportion were assessed using increment cores. We did a spatial analysis to take into account environmental heterogeneity at the tree level, and we fitted a multi-trait, Bayesian MCMC (Markov Chain Monte Carlo) genetic model. Our study confirmed, in most situations, that HL expressed heterosis over its best parent for growth traits taking advantage of an early faster growth, with no loss in wood density. However, growth traits showed low levels of heritability. On the other hand, bud flush and stem flexuosity had high heritabilities, and wood density was clearly under JL control. Site-dependent heritabilities were expressed by EL. Additive genetic correlations were presented. The traits with high heritabilities showed high correlation between their performances in pure species and in hybridization, as well as high across-site correlations. The discussion focused on the interest of these genetic parameters for the hybrid larch breeding programs.
\end{abstract}

Keywords: interspecific hybrid; diallel mating design; multi-site progeny test; growth; wood density; multitrait model; Bayesian inference

\footnotetext{
${ }^{*}$ Published in Tree Genetics \& Genomes, october 2017 https://doi.org/10.1007/s11295-017-1177-1

${ }^{\dagger}$ Luc E. Pâques

E-mail: luc.paques@inra.fr
} 
Version définitive du manuscrit publié dans / Final version of the manuscript published in : Tree Genetics \& Genomes, october 2017, https://doi.org/10.1007/s11295-017-1177-1

\section{Introduction}

Inter-specific hybridization is a common breeding strategy used in forest tree improvement. Commercial hybrids are produced for several species including poplars and aspens ( $\mathrm{Li}$ et al, 1993), eucalypts, sub-tropical pines (reviewed by Nikles and Griffin, 1991), and larches (reviewed by Pâques, 2013). For foresters, hybrids are often interesting because of their superiority over their parental species for several traits of ecological and economic importance (Zobel and Talbert, 1984).

Although there is an abundant literature on the topic of heterosis, this term remains somewhat ambiguous. Some authors prefer to associate heterosis to non-additive gene effects expressed in hybrids, and sometimes add the complementarity between parental traits under additive control to the definition of hybrid vigor (Nikles and Griffin, 1991). Nevertheless, 'heterosis' was originally defined as a free-of-hypothesis concept, synonymous of 'hybrid vigor' (Shull, 1948). For a given quantitative trait, heterosis is considered as the difference between the hybrid and the mid-parent value (Falconer and Mackay, 1996). The best-parent heterosis, i.e. the difference between the hybrid and its best parent, is often preferred because it highlights perspectives in terms of breeding (Kearsey and Pooni, 1996; Dungey, 2001). In the present paper, heterosis will also be assumed a free-of-hypothesis concept, and will refer by default to best-parent heterosis. An extra ambiguity comes from the definition of 'hybrid'. Indeed, a 'hybrid' may refer to the cross between inbred lines, between populations, or between different species. Mechanisms underlying the heterosis of hybrids between inbred lines (e.g. maize lines) start to be well understood (Gallais, 2009; Baranwal et al, 2012; Chen, 2013); whereas the mechanisms behind the heterosis of inter-population and inter-species hybrids, i.e. hybrids between heterozygous parents, remain poorly documented (Perron, 2008)(see Li and $\mathrm{Wu}, 1996$, though).

Despite the sparse information about the mechanisms, forest tree geneticists have well documented the superiority of some inter-populations and interspecific forest trees hybrids (Nikles and Griffin, 1991; Li et al, 1993; Pâques, 2013). However, this superiority over some commercial references, which is the final aim of a hybrid breeding program, does not provide information on the genetic architecture of the performances of the hybrid. At best, the study of heterosis by means of a proper mating design, and therefore proper parental references, allows the estimation of genetic parameters such as variance components (Hinkelmann, 1974) which can in turn be used to choose and develop a breeding strategy (Falconer and Mackay, 1996). In addition, the expression of heterosis may change with time and environmental condi- tions and its study, therefore, would require long-term multi-site experimentation. As an illustration, it can be demonstrated that genotype-by-environment interactions $(\mathrm{G} \times \mathrm{E})$ alone can theoretically lead to heterosis including best-parent heterosis (Knight, 1973). Practical examples of the link between heterosis and $\mathrm{G} \times \mathrm{E}$ are also available. Thus, heterosis may be conditional to the site as shown by $\mathrm{Li}$ and $\mathrm{Wu}$ (1997) for aspen and by Weng et al (2014) for Eucalyptus urophylla $\times$ E. tereticornis. The $\mathrm{G} \times \mathrm{E}$ may not only manifest on the means but also on the components of variance. For instance, the parental contribution of Pinus caribaea var. hondurensis and $P$. tecunumanii to their hybrid heritability depends on the testing site (Mutete et al, 2015). Unfortunately, the creation of proper mating designs and the establishment of multi-site field trials over contrasted environments are often complicated by the species biology (crossing of 2 different species), expensive and time-consuming. Therefore such assays of true heterosis are rare in the forestry literature.

Hybridization between several species of larches (Larix decidua Mill., L. kaempferi (Lamb.) Carr. and L. laricina (Du Roi) K. Koch) is possible and the hybrid between European (L. decidua) and Japanese ( $L$. kaempferi) larches (respectively EL and JL) particularly shows promising prospects for forestry in Europe and North-America (Pâques, 1992b; Baltunis et al, 1998; Greenwood et al, 2015). Hereafter, 'hybrid larch' (HL) will exclusively refer to $L$. decidua $\times$ L. kaempferi or its reciprocal $L$. kaempferi $\times L$. decidua. The superiority of HL for height over its parents has been described in the literature, as reviewed by Pâques (1989, 2013). Depending on the site, HL can outperform either EL, JL, or both. This superiority justifies the existence of several hybrid larch breeding programs, in Europe and abroad (Perron, 2008). In addition to the heterosis on growth traits, HL inherits canker resistance from JL (Sylvestre-Guinot et al, 1999), which is of critical importance for lowland cultivation of EL in Western Europe.

However, the comparison of hybrid to its true parental references, i.e. heterosis sensu stricto, is poorly documented for larches (Pâques, 1989, 2013). Heterosis on growth traits was confirmed for HL at a juvenile stage (Baltunis et al, 1998; Pâques, 2002) and, more recently, on 22-years-old trees (Greenwood et al, 2015). In a breeding perspective, there is also a need for identifying the role of each parent species in the genetic control of the hybrid traits. Using 2 factorial mating designs, Pâques (2004) could identify the parental contribution to the phenotype of 16-years-old hybrid larches. He distinguished traits whose variability was more under Japanese parent control, such as stem volume and flexuosity.

In summary, while hybrid superiority has been shown for hybrid larch, true heterosis is still poorly docu- 
Version définitive du manuscrit publié dans / Final version of the manuscript published in :

Tree Genetics \& Genomes, october 2017, https://doi.org/10.1007/s11295-017-1177-1

mented because of the absence of proper experiments, as discussed before. Multisite, long-term, well designed experiments are of primary importance in order to gather reliable estimations of the genetic parameters needed to plan a hybrid larch breeding strategy (Pâques, 1989). To our knowledge, hybrid larch heterosis has never been studied with such an experiment yet. The first part of this study attempted to show for which trait and which amplitude one can expect heterosis from hybrid larch. True heterosis was assessed by the mean of a diallel mating design. The question of whether heterosis would be a juvenile character was addressed together with that of the impact of the environment on its expression. A better knowledge of the quantitative genetics of the traits should help us to better define a breeding strategy, and to define where and how efforts should be emphasized. For this reason, we investigated the importance of additive and non-additive genetic variances, the magnitude of genetic correlations, as well as the relative contribution of parental species in the genetic control of hybrid traits. We made a choice of solving such a complex genetic model in a Bayesian framework using MCMC techniques. Indeed, this framework brings the desirable feature of integrating estimation, prediction, and decision into a single analytical process (Gianola et al, 1989). Finally, the hypothesis of a better buffering of environmental constraints by hybrids vs. parental species was tested through a preliminary study of stability of species and hybrids across environments ( $\mathrm{G} \times \mathrm{E}$ interaction).

\section{Materials and Methods}

\subsection{Experimental population}

Nine (9) EL parents from Sudetan Mountains (Czech Republic) and 9 JL parents from various Hondo Island origins (Japan) were sampled from INRA (Institut National de la Recherche Agronomique) EL and JL breeding populations and crossed following a full diallel mating design producing pure species and hybrid full-sib progenies. Parents involved in the experiment were selected at random among trees able to flower and to produce cones. Out of the 171 possible families (that is 324 crosses, a family being a cross plus its reciprocal), self-crosses mostly failed and none of them were field tested, and for 8 families ( 7 EL families and 1 HL family) no offspring were available. The remaining 145 families were represented by one cross and/or its reciprocal. In each site where the diallel was set up there were between 18 and 29 EL families, between 25 and 28 JL families, and between 56 and 71 HL families; the families were represented by 1 to 63 trees per site, with a mean of 23.2 trees. Thirty-six (36) extra full-sib and half-sib families, each having one of the parents of the diallel, were added to the main design. Details of available crosses are summarized in Appendix 1, Table 3-5. All seeds were sown at INRA nursery in Orléans (France) in spring 1995. Then 2-years-old bare-root seedlings were planted in 3 ecologically contrasted sites in spring 1997: Saint-Appolinaire (abbreviated SA), Saint-Saud (SS) and Cumières (not considered in this study because of a too high mortality), following a single-tree randomized incomplete blocks (RIB) design. To replace the Cumières site, 1311 trees were randomly sampled in SS, and 3 scions were collected from each of these trees and grafted on 2-year-old seedling. Because of the scarcity of available rootstocks, 2 scions were grafted on HL rootstocks (half-sib EL $\times$ JL hybrids) and the last one was grafted on a JL rootstock (from a commercial seedlot). The grafted trees were grown for 2 years in PNRGF (PÃtle National des Ressources Génétiques Forestières) nursery at Peyrat-le-Château (abbreviated PC). Resulting material was planted in spring 2004 in PC vicinity, following a RIB design with 3 -tree row plots (the 3 scions from the same ortet together). On all 3 sites, progenies from the 3 taxa were randomly allocated to each block. We favored this option in order to better take into account micro-environmental effects.

The site of SA is established at the eastern edge of the Massif Central range in a mountainous area on a steep southern-aspect slope. On the contrary, the sites of $\mathrm{SS}$ and $\mathrm{PC}$ are located at lower elevations on the western edge of Massif Central on mostly flat areas, under oceanic influence. The site of SS was a former grassland, frequently fertilized, whereas the other sites were already forest lands in the past. Description of the sites is provided in Appendix 1, Table 6. Two thinning treatments were applied to SS: in early 2004 and in 2010. During the first thinning, $30 \%$ of the poorest performing trees (based on a selection index combining volume and flexuosity) within each family were removed. The second thinning favored an even spatial distribution of remaining trees, like in forest production. No thinning was applied to the 2 other sites. Counts of trees per family and per site, as well as the evolution of the number of trees due to mortality and thinning, is provided in Appendix 1, Fig. 4.

\subsection{Measurements}

Trees were measured several times from plantation to winter 2010 in SA, and to winter 2014 in SS and in PC. Measurements included breast-height circumference (BHC), total height (HT), stem flexuosity (FLX) and bud flush (BUD), and concerned all available trees at each assessment (except for SA in 2005). Stem flexuosity and terminal bud flushing were visually assessed using subjective scoring scales, following Keiding and Olsen (1965)(see Pâques, 1992b) for flexuosity (from 5: 
Version définitive du manuscrit publié dans / Final version of the manuscript published in :

Tree Genetics \& Genomes, october 2017, https://doi.org/10.1007/s11295-017-1177-1

straight stem to 1: stems with several severe crooks) and Gauchat and Pâques (2011)(Fig. 1) for bud flush (from 0: dormant bud to 5: elongated needles, 1-2 cm in open rosette; plus an extra class 6: stem elongation). Each observation of bud flush at any given site was done in a single day. Diameter increment cores were harvested at breast height in the 3 sites over two or three collecting periods depending on site (Appendix 1, Table 7). All individuals in SA and SS trials were sampled, with a special effort in SS for harvesting increment cores from trees before being thinned. In PC, only 1 ramet per ortet was randomly sampled. Increment cores were dried off, sawn in $2 \mathrm{~mm}$-thick axial boards and then X-rayed on negative films. Out of the two, only the pith to bark radius with the least defects (resin pockets, knots, compression wood) was kept for subsequent analysis. Microdensitometric profiles were produced from high resolution scans of the $\mathrm{X}$-rayed films using WinDENDRO ${ }^{\mathrm{TM}}$ (Regent Instruments Canada Inc., 2008). From microdensitometric profiles we visually delimited annual ring increments, which were used to estimate yearly $\mathrm{BHC}$ values. Inferred BHC from annual ring increments $(\Delta)$ for year $n+1$ was:

$$
B H C_{n+1}=B H C_{n}+2 \pi \times \Delta_{n+1} \times \delta
$$

with $\delta$ being an individual correction term, calculated as the ratio between difference in radius calculated from BHC measures and difference in radius calculated from ring increments, assuming a circular stem section and a constant bark thickness. Overall wood density $\left(D E N_{n}\right)$ over years was calculated from the ring mean densities $(d)$ weighted by the corresponding ring surfaces $(\mathrm{S})$ : we used as the first ring the one for which enough observations were available $\left(i_{0}=2000\right.$ in SA and SS and $i_{0}=2007$ in PC, that is constantly 4 years after plantation, for which at least $50 \%$ of the ring observations were available in each site).

$D E N_{n}=\frac{\sum_{i=i_{1}}^{n} d_{i} \times S_{i}}{\sum_{i=i_{1}}^{n} S_{i}}$ with $S_{i}=\frac{B H C_{i}^{2}-B H C_{i-1}^{2}}{4 \pi}$

Delimitation between sapwood and heartwood was visually assessed on the boards based on color differences, and heartwood surface proportion (HWP) was calculated for 2009 and 2011 in SS, for 2013 in SA, and for 2014 in PC. All the traits (BHC, HT, DEN, HWP, FLX and BUD) were analyzed without any transformation.

\section{3 $\quad$ Models}

The data were analysed using a two-step approach. Firstly, we fitted a model M1 that aimed to estimate the taxa means, from which we assessed best-parent heterosis at the species level. Model M1 was fitted for each combination of site, age and trait; it took into account genetic and spatial environmental sources of variation. All 4 taxa (EL, JL, EL $\times$ JL and $\mathrm{JL} \times \mathrm{EL}$ ) were analyzed simultaneously, including all available genetic material, at the tree level, so that (i) the contrasts between taxa were directly estimated and (ii) the spatial variance estimation used all available information within each trial. Estimating simultaneously genetic and spatial effects was computationally costly. For this reason M1 was a uni-trait model, meaning it ignored information across traits. However, traits are usually correlated both at genetic and environmental levels. This can be leveraged with a multi-trait analysis, gaining more insight on the genetic merits for each individual trait (e.g. Marchal et al, 2016), but also allowing for inference on the genetic cross-correlations. For these reasons, as a second step, we fitted a genetic model M2 that was multi-trait. The spatial effects estimated in M1 were subtracted from the phenotype before processing to the second step.

Model M2 was fitted for each combination of site and taxon; with the goal to estimate the genetic variance parameters such as heritabilities and genetic correlations between traits. Model M2 was also used to predict the genetic performances of the 18 parents of the diallel. The stability of these performances across sites, as well as their stability in pure species vs. in hybridization, were assessed by the mean of Pearson correlations. At this second step of M2, we used a Bayesian framework in order to infer directly the genetic parameters using posterior distributions. Attention must be drawn here on the terminology and concepts attached to the use of Bayesian approaches that differ from those in M1 that followed a frequentist approach. While the former makes decisions about the magnitude and relevance of estimates based on posterior distributions, the latter uses hypothesis testing and confidence intervals. With the choice of a Bayesian framework in M2, we focused on the magnitude of the genetic parameters and the uncertainty around their estimations, because these are the pieces of information that ultimately can guide breeders in their selection decisions.

\subsection{Model M1 - heterosis estimation}

Each trait at each age in each site $(y)$ was analyzed with the model M1 that took the form:

$$
y_{t r i j k l}=\text { fixed }_{t r}+\text { genet }_{t i j k}+e n v t_{l}
$$

with fixed the fixed effects at the taxon level, genet the individual random genetic effects, and envt the individual random environmental effects. The fixed effects took the form: 
Version définitive du manuscrit publié dans / Final version of the manuscript published in : Tree Genetics \& Genomes, october 2017, https://doi.org/10.1007/s11295-017-1177-1

$$
\text { fixed }_{t r}=\left\{\begin{array}{c}
\beta_{0}+\beta_{E}+\iota_{P C} \gamma_{E: r} \text { if } \mathrm{t}=\text { 'EL' } \\
\beta_{0}+\beta_{J}+\iota_{P C} \gamma_{J: r} \text { if } \mathrm{t}=\text { 'JL' } \\
\beta_{0}+\iota_{P C} \gamma_{H: r} \text { if } \mathrm{t}=\text { 'EL } \times \mathrm{JL} \\
\beta_{0}+\beta_{J \times E}+\iota_{P C} \gamma_{H: r} \text { if } \mathrm{t}=\text { 'JL } \times \mathrm{EL}
\end{array}\right.
$$

(M1a)

The fixed effects of M1 were $\beta_{0}$, the $\mathrm{EL} \times \mathrm{JL}$ taxon mean used as a reference; and $\beta_{E}, \beta_{J}, \beta_{J \times E}$, the contrasts between each taxon $t$ and the reference $\mathrm{EL} \times \mathrm{JL}$. The indicative variable $\iota_{P C}$ was defined such as the hybrid rootstock effect $\gamma_{t: r}$ were only accounted in the site PC. The hybrid rootstock effects $\gamma_{t: r}$ were calculated as contrasts between the trees whose rootstock $r$ was HL compared to the trees whose rootstock $r$ was JL; this effect included an interaction between rootstock species and scion species. The rootstock effects estimates in PC were presented in Appendix 2, Fig. 5. The genetic effects took the form:

genet $_{t i j k}=\left\{\begin{array}{c}a_{E: i}+d_{E: i}+\iota_{P C} c_{E: i} \text { if } \mathrm{t}={ }^{\prime} \mathrm{EL} \\ a_{J: i}+d_{J: i}+\iota_{P C} c_{J: i} \text { if } \mathrm{t}=\text { 'JL' } \\ h_{E: j}+h_{J: k}+f_{j k}+c_{H: i} \text { if } \mathrm{t}=\text { ' } \mathrm{EL} \times \mathrm{JL} \\ h_{E: k}+h_{J: j}+f_{k j}+c_{H: i} \text { if } \mathrm{t}=\text { 'JL } \times \mathrm{EL}\end{array}\right.$

For pure species, the additive effect or breeding value $(\mathrm{BV})$ of the genotype $i$ (that is, an individual tree in $\mathrm{SA}$ and $\mathrm{SS}$ and a clonal genotype in $\mathrm{PC}$ ) was $a_{E} \sim N\left(0, \sigma_{A E}^{2} \mathbf{A}_{\mathbf{E}}\right)$ or $a_{J} \sim N\left(0, \sigma_{A J}^{2} \mathbf{A}_{\mathbf{J}}\right)$ for EL or JL larches respectively, with $\mathbf{A}_{\mathbf{E}}$ and $\mathbf{A}_{\mathbf{J}}$ the additive relationship matrices. Dominance effects were $d_{E} \sim$ $N\left(0, \sigma_{D E}^{2} \mathbf{D}_{\mathbf{E}}\right)$ or $d_{J} \sim N\left(0, \sigma_{D J}^{2} \mathbf{D}_{\mathbf{J}}\right)$ for $\mathrm{EL}$ or $\mathrm{JL}$ larches respectively, with $\mathbf{D}_{\mathbf{E}}$ and $\mathbf{D}_{\mathbf{J}}$ the dominance relationship matrices. For hybrids, we used a Stuber and Cockerham (1966) model. The general hybridization abilities (GHA) from the mother $j$ and the father $k$ were $h_{E} \sim N\left(0, \sigma_{H E}^{2} \mathbf{I}_{\mathbf{H E}}\right)$ and $h_{J} \sim N\left(0, \sigma_{H J}^{2} \mathbf{I}_{\mathbf{H J}}\right)$, assuming unrelated, non-inbred parents (coancestry matrices for parents were half-identity matrices). This model also assumed that L. kaempferi $(2 \mathrm{n}=24)$ and L. decidua $(2 \mathrm{n}=24)$ contributed to the same extent to the hybrid nuclear genome, as Nkongolo and Klimaszewska (1995) showed in in vitro embryogenic lines of EL $\times$ JL karyotypes ranging between $2 \mathrm{n}=24$ and $2 \mathrm{n}$ $=25$. The dominance variance was captured using a hybrid family effect, or specific hybridization ability (SCA): $f \sim N\left(0, \sigma_{D H}^{2} \mathbf{F}\right)$ (Lo et al, 1997; Cros, 2014). As self-crosses were absent and diallel parents were assumed to be unrelated and non-inbred, $\mathbf{F}=\frac{1}{4} \mathbf{I}_{\mathbf{F}}$. A random clonal effect $c$ was added (i) in PC for all taxa, in order to capture the epistasis and the nongenetic effects associated with each ortet (except for traits measured from the increment cores in PC, as no clonal repetition was available for them) and (ii) for all sites with HL only, in order to capture the within-family Mendelian segregation genetic variance and thus to separate it from the residual. The clonal effects had taxon specific variances.

$$
e n v t_{l}=s_{l}+e_{l}
$$

Environmental heterogeneity was assumed to be spatially structured, so that the spatial effect at location 1 was $s \sim N\left(0, \sigma_{S}^{2} \mathbf{S}\right)$ with $\mathbf{S}=\left\{\rho^{\text {distance }(a, b)}\right\}$ where $\rho$ had to be estimated for each combination of trait, age and site. Spatial correlation matrices $\mathbf{S}$ were built using the R package fields (Nychka et al, 2015; R Core Team, 2015). Finally $e \sim N\left(0, \sigma_{E}^{2} \mathbf{I}_{\mathbf{R}}\right)$ were the unstructured residuals, common to the 4 taxa; its variance was $\sigma_{E}^{2}$. All single-trait models were fitted using restricted ML (REML) and the $\mathrm{R}$ package breedR (Muñoz and Sánchez, 2015).

For computational reasons $\rho$ was estimated by Maximum Likelihood (ML) before the genetic effects were included in the model. Once $\rho$ estimated, the spatial variance $\sigma_{S}^{2}$ was obtained at the same estimation step as the other variance components. Estimates of $\rho$ and spatial variance proportion (SVP) that we defined as $\mathrm{SVP}=\sigma_{S}^{2} /\left(\sigma_{E}^{2}+\sigma_{S}^{2}\right)$ were presented in Appendix 2, Table 9. For 2 traits in PC (FLX at 11-years-old and BUD at 3-years-old), $\rho$ was estimated to be low (0.69 and 0.63 respectively), correspondingly with very high SVP over $99 \%$ in both cases (results not shown). Such a parameterization of $\rho$ may lead to a confusion between $\sigma_{S}^{2}$ and the residual variance $\sigma_{E}^{2}$. Therefore, for these traits in PC we did not use the ML estimation for $\rho$ but we fixed $\rho=0.99$ instead.

\subsection{Taxa means and heterosis}

Using model M1 (including all taxa simultaneously), we estimated directly the contrast between each taxon mean and the reference EL $\times$ JL. Doing this way, we measured the best-parent heterosis where appropriate, or the parental superiority otherwise; and we obtained a standard error for each contrast estimation. We used the standard errors of these contrasts to estimate confidence intervals and we computed p-values (null hypothesis: âĂIJthe contrast is nullâĂ $\dot{\mathrm{I}}$ ) under Gaussian distribution assumption.

\subsection{Model M2 - variance parameters estimation}

Model M2 was independently fitted for each combination of site and taxon: EL, JL, and HL $(\mathrm{EL} \times \mathrm{JL}$ and $\mathrm{JL} \times \mathrm{EL}$ pooled together, assuming no reciprocal effects), on data previously adjusted for spatial heterogeneity. The response variables $y$ of M2 were the observations of all $p$ traits from which were subtracted the spatial effects predicted with model M1. In PC, we also subtracted the rootstock species effect $\gamma$ estimated with M1. Multi-trait analysis is also known to account 
Version définitive du manuscrit publié dans / Final version of the manuscript published in :

Tree Genetics \& Genomes, october 2017, https://doi.org/10.1007/s11295-017-1177-1

properly for individuals that are censored (the case in SS due to thinning; and non-sampled individuals for increment cores traits in PC) in the estimation of genetic parameters (Wei and Borralho, 1998). Therefore in SS some traits (BHC, HT, DEN and FLX) were also included at a young stage in order to take into ac- count the thinning censure; they were then considered as new traits. All included BHC were field measured, not inferred from ring increments. Exact ages for all traits involved in M2 are given in Appendix 1, Table 8. For pure species EL and JL, model M2 took the form:

$$
\left(\begin{array}{c}
y_{1} \\
y_{2} \\
\vdots \\
y_{p}
\end{array}\right)_{i l}=\left(\begin{array}{c}
m_{1} \\
m_{2} \\
\vdots \\
m_{p}
\end{array}\right)+\left(\begin{array}{c}
a_{1} \\
a_{2} \\
\vdots \\
a_{p}
\end{array}\right)_{i}+\left(\begin{array}{c}
d_{1} \\
d_{2} \\
\vdots \\
d_{p}
\end{array}\right)_{i}+\iota_{P C}\left(\begin{array}{c}
c_{1} \\
c_{2} \\
\vdots \\
c_{p}
\end{array}\right)_{i}+\left(\begin{array}{c}
e_{1} \\
e_{2} \\
\vdots \\
e_{p}
\end{array}\right)_{l}=m+a_{i}+d_{i}+\iota_{P C} c_{i}+e_{l}
$$

The overall means were $m$. A complete variance-covariance matrix was used to structure the additive effects distribution, that is $a \sim N\left(0, \boldsymbol{\Sigma}_{\mathbf{A}} \otimes \mathbf{A}\right)$ with:

$$
\boldsymbol{\Sigma}_{\mathbf{A}}=\left(\begin{array}{cccc}
\sigma_{A 1}^{2} & r_{A: 12} \sigma_{A 1} \sigma_{A 2} & \ldots & r_{A: 1 p} \sigma_{A 1} \sigma_{A p} \\
r_{A: 12} \sigma_{A 1} \sigma_{A 2} & \sigma_{A 2}^{2} & \ldots & r_{A: 2 p} \sigma_{A 2} \sigma_{A p} \\
\vdots & \vdots & \ddots & \vdots \\
r_{A: 1 p} \sigma_{A 1} \sigma_{A p} & r_{A: 2 p} \sigma_{A 2} \sigma_{A p} & \ldots & \sigma_{A p}^{2}
\end{array}\right)
$$

The additive genetic correlation between traits $r_{A}$ were thus estimated as the model was fitted. Dominance effects were independent between traits, that is $d \sim N\left(0, \boldsymbol{\Sigma}_{\mathbf{D}} \otimes \mathbf{D}\right)$ with:

$$
\boldsymbol{\Sigma}_{\mathbf{D}}=\left(\begin{array}{cccc}
\sigma_{D 1}^{2} & 0 & \cdots & 0 \\
0 & \sigma_{D 2}^{2} & \cdots & 0 \\
\vdots & \vdots & \ddots & \vdots \\
0 & 0 & \cdots & \sigma_{D p}^{2}
\end{array}\right)
$$

Properly conditioned inverse matrices $\mathbf{A}^{-\mathbf{1}}$ and $\mathbf{D}^{-\mathbf{1}}$ were built directly using $\mathrm{R}$ packages MCMCglmm (Hadfield, 2010) and nadiv (Wolak, 2012). A complete variance-covariance matrix was also used to structure the residual effects distribution $e \sim N\left(0, \mathbf{\Sigma}_{\mathbf{R}} \otimes \mathbf{I}_{\mathbf{R}}\right)$ so that residual correlations between traits $r_{R}$ were estimated. In PC only, we added an unstructured, independent between traits, clonal effect $c \sim N\left(0, \boldsymbol{\Sigma}_{\mathbf{C}} \otimes \mathbf{I}_{\mathbf{C}}\right)$. Again, Stuber and Cockerham (1966) model was applied for hybrids, following model M2b:

$$
\left(\begin{array}{c}
y_{1} \\
y_{2} \\
\vdots \\
y_{p}
\end{array}\right)_{i j k l}=\left(\begin{array}{c}
m_{1} \\
m_{2} \\
\vdots \\
m_{p}
\end{array}\right)+\left(\begin{array}{c}
h_{E: 1} \\
h_{E: 2} \\
\vdots \\
h_{E: p}
\end{array}\right)_{j}+\left(\begin{array}{c}
h_{J: 1} \\
h_{J: 2} \\
\vdots \\
h_{J: p}
\end{array}\right)_{k}+\left(\begin{array}{c}
f_{1} \\
f_{2} \\
\vdots \\
f_{p}
\end{array}\right)_{j k}+\iota_{P C}\left(\begin{array}{c}
c_{1} \\
c_{2} \\
\vdots \\
c_{p}
\end{array}\right)_{i}+\left(\begin{array}{c}
r_{1} \\
r_{2} \\
\vdots \\
r_{p}
\end{array}\right)=m+h_{E: j}+h_{J: k}+f_{j k}+\iota_{P C} c_{i}+r_{l}
$$

Additive variances in hybridization were structured Wishart $\left(W^{-1}\right)$ distributions. We used parameter exusing complete variance-covariance matrices $h_{E} \sim N(0$, pansion (PX) (Liu et al, 1998) for the additive com$\left.\boldsymbol{\Sigma}_{\mathbf{H E}} \otimes \mathbf{I}_{\mathbf{H E}}\right)$ and $h_{J} \sim N\left(0, \boldsymbol{\Sigma}_{\mathbf{H J}} \otimes \mathbf{I}_{\mathbf{H J}}\right)$ so that $r_{H E} \quad$ ponents: $\boldsymbol{\Sigma}_{\mathbf{A}}=\operatorname{diag}\left(\alpha_{A}\right) \boldsymbol{\Sigma}_{\mathbf{A} \alpha} \operatorname{diag}\left(\alpha_{A}\right)$, with $\boldsymbol{\Sigma}_{\mathbf{A} \alpha} \sim$ and $r_{H J}$, the components of additive genetic correlation in the hybrids due to each of the parental species, were estimated. The family effects were independent $f \sim N\left(0, \boldsymbol{\Sigma}_{\mathbf{D}} \otimes \mathbf{F}\right)$ Similarly to $\mathrm{M} 2 \mathrm{a}$, the residual effects distribution was $r \sim N\left(0, \boldsymbol{\Sigma}_{\mathbf{R}} \otimes \mathbf{I}_{\mathbf{R}}\right)$ Once again, we added an unstructured, independent between traits, clonal effect in PC.

The models were fitted using Markov Chain Monte Carlo (MCMC) with the R package MCMCglmm (Hadfield, 2010). Means priors were vague with $m \sim N(0$, $W^{-1}\left(\mathbf{V}=\mathbf{I}_{\mathbf{p}}, \nu=p+1\right)$ and working parameters $\alpha_{A} \sim N\left(0,10^{3} \mathbf{I}_{\mathbf{p}}\right)$. For hybrids, we used PX for $\boldsymbol{\Sigma}_{\mathbf{H E}}$ and $\boldsymbol{\Sigma}_{\mathbf{H J}}$ with the same hyperparameters. On one hand, PX allows a better mixing of the chains. On the other hand, it avoids the modal shape of $W^{-1}$ and it allows close-to-zero estimation for marginal variances (Gelman, 2006; Hadfield, 2010). The hyperparameters $\mathbf{V}=\mathbf{I}_{\mathbf{p}}$ and $\nu=p+1$ were set following Gelman and Hill (2007)(p. 286) in order to set marginal correlations priors to be uniform on $[-1 ; 1]$. To our knowl${ }^{10}{ }^{10} \mathbf{I}_{\mathbf{p}}$ ). Variance-covariance matrices priors were inversedge, the effect of PX on the marginal correlations 
Version définitive du manuscrit publié dans / Final version of the manuscript published in : Tree Genetics \& Genomes, october 2017,

priors remains undocumented. For this reason and to check any eventual impact we sampled $10^{5}$ values in the parameter expanded inverse-Wishart distribution, with the same parameterization, and we used MonteCarlo to draw the marginal correlation prior distribution. We visually assessed that it remained uniform on $[-1,1]$ (result not shown). Parameter expansion was also set for dominance variances so that for each trait $\sigma_{D \alpha}^{2} \sim W^{-1}(V=1, \nu=2)$ with working parameters $\alpha_{D} \sim N\left(0,10^{3} \mathbf{I}_{\mathbf{p}}\right)$. We used Sorensen and Gianola (2007)(p. 579) improper uniform prior for the residuals $\Sigma_{R} \sim W^{-1}\left(\mathbf{V}=10^{-10} \mathbf{I}_{\mathbf{p}}, \nu=-(p+1)\right)$. Marginal residual correlations estimations are provided in Appendix 2, Fig. 7. In PC and for the hybrids, the clonal effect variance prior was also set improper uniform so that for each trait $\sigma_{C}^{2} \sim W^{-1}\left(V=10^{-10}, \nu=-2\right)$. All chains were at least $1.5 \times 10^{6}$ iterations long (up to $10.5 \times 10^{6}$ long, depending on the taxon and site combination) with $5 \times 10^{5}$ iteration burn-in, and a regular thinning so that $10^{3}$ uncorrelated samples from each chain were finally kept for inference.

\subsection{Variance parameters}

The genetic variance parameters were estimated from M2 only. For pure species, the phenotypic variance was $\sigma_{P}^{2}=\sigma_{A}^{2}+\sigma_{D}^{2}+\sigma_{R}^{2}$ as in this case $\sigma_{R}^{2}$ the residual variance from the model was equal to $\sigma_{E}^{2}$ the environmental variance, i.e. the variance of non-genetic effects (epistasis was neglected). The narrow-sense heritability was $h^{2}=\sigma_{A}^{2} / \sigma_{P}^{2}$. For hybrids we fitted a model at the family level, therefore due to Mendelian segregation part of the genetic variance expressed at the individual level was captured by the residual variance $\sigma_{R}^{2}$. The individual level phenotypic variance was $\sigma_{P}^{2}=\sigma_{G H A: E}^{2}+\sigma_{G H A: J}^{2}+\sigma_{S C A}^{2}+\sigma_{R}^{2}=\frac{1}{2} \sigma_{H E}^{2}+\frac{1}{2} \sigma_{H J}^{2}+$ $\frac{1}{4} \sigma_{D}^{2}+\sigma_{R}^{2}$. Given that $\sigma_{R}^{2}=\sigma_{E}^{2}+\frac{1}{2} \sigma_{H E}^{2}+\frac{1}{2} \sigma_{H J}^{2}+$ $\frac{3}{4} \sigma_{D}^{2}$ (Lo et al, 1997), $\sigma_{P}^{2}=\sigma_{H E}^{2}+\sigma_{H J}^{2}+\sigma_{D}^{2}+\sigma_{E}^{2}$ showing an analogy with pure species variance decomposition. In $\mathrm{PC}$, we included the clonal variance $\sigma_{P}^{2}=\sigma_{A}^{2}+\sigma_{D}^{2}+\sigma_{C}^{2}+\sigma_{R}^{2}$ for pure species and $\sigma_{P}^{2}=$ $\frac{1}{2} \sigma_{H E}^{2}+\frac{1}{2} \sigma_{H J}^{2}+\frac{1}{4} \sigma_{D}^{2}+\sigma_{C}^{2}+\sigma_{R}^{2}$ for hybrids. We defined the hybrid heritabilities as $h_{E}^{2}=\sigma_{H E}^{2} / \sigma_{P}^{2}$ and $h_{J}^{2}=\sigma_{H J}^{2} / \sigma_{P}^{2}$ (Stuber and Cockerham, 1966; Cros, 2014), these heritabilities being analogous to half their pure species counterparts. Degree of dominance $d^{2}=$ $\sigma_{D}^{2} / \sigma_{P}^{2}$, residual correlations $\left(r_{R}\right)$ and coefficients of variations $C V=\sigma_{P} / m$ along with taxa means $(\mathrm{m})$ were provided for all taxa in Appendix 2 (Figure 6, Figure 7 and Table 9 respectively). We used the variance components Markov chains to produce Markov chains of $h^{2}, d^{2}$ and the genetic and residual correlations and we computed $95 \%$ credibility intervals (CIs) of these parameters.

\subsection{Parents performances}

For each trait and site, we predicted BV and GHA for the 18 parents of the diallel using model M2. Individual performances of both intra- and inter-specific crosses of the $9 \mathrm{EL}$ and the $9 \mathrm{JL}$ parents are presented with 95\% CIs in Appendix 3, Fig. 8-10 for the most heritable traits (bud flush, flexuosity and density). We assessed the across-sites stability of BV and GHA by the mean of Pearson correlations between the parents' performances in each site; moreover, a visual representation of the $\mathrm{G} \times \mathrm{E}$ stability of the 18 parents is provided for the most heritable traits in Appendix 3, Fig. 11. In the same way, we calculated the Pearson correlations between $\mathrm{BV}$ and GHA $\left(r_{B V, G H A}\right)$ in order to assess the stability of performances in pure species vs. in hybridization. For both the across-site stability and the stability in hybridization, we used the parents' performances Markov chains to produce Markov chains of the Pearson correlations and we checked if their $95 \%$ CIs exceeded some given thresholds $(0,0.3$, 0.6 and 0.9$)$.

\section{Results}

\subsection{Importance of reciprocal effects and rootstock effects in the model M1}

Although some reciprocal effects $\left(\beta_{J \times E}\right.$, designed as a contrast between $\mathrm{JL} \times \mathrm{EL}$ and $\mathrm{EL} \times \mathrm{JL}$, Cf equation M1a) were significant (density in SS, 2 and 3 year height in $\mathrm{SA})(p<0.05$ to $p<0.01)$, their magnitude was low (up to âA $\breve{S} 8.29 \mathrm{~kg} . \mathrm{m}-3$ for density in SS and up to $+6.23 \mathrm{~cm}$ for height in SA) (Fig 1, d, g, h). For all other traits (BHC (Fig 1, a-c), height and density in the other sites (Fig 1, e-f, g, i), flexuosity (Fig 1, j-l), bud flush (results not shown) and HWP (results not shown)) reciprocal effects were very small and not significant. Therefore, we took EL $\times$ JL as the reference (HL) for heterosis assessment, with negative contrasts ( $\beta_{J}$ and $\beta_{E}$ in equation M1a) indicating heterosis, and positive contrasts parental superiority.

In the particular case of PC, we found strong, positive, significant rootstock species effects ( $\gamma$ in equation M1a) for growth traits (Appendix 2, Fig. 5 a-b) ( $p<10^{-5}$ at the older age, for both $\mathrm{BHC}$ and height). Depending on the scion species, the effect of hybrid rootstock compared to Japanese rootstock varied between $7.3 \mathrm{~cm}$ and $5.5 \mathrm{~cm}$ for $\mathrm{BHC}$ at age 11 . For height, there might be an interaction between the scion species and the rootstock species, JL scions seemed to undergo a lower HL rootstock effect. Thus for height the rootstock effect varied between $90.4 \mathrm{~cm}$ for EL scions and $48.3 \mathrm{~cm}$ for JL scions at age 11 . Rootstock effects for the other traits were low though sparsely significant (Appendix 2, Fig. $5 \mathrm{c}$-d, and unpresented 
Version définitive du manuscrit publié dans / Final version of the manuscript published in :

Tree Genetics \& Genomes, october 2017, https://doi.org/10.1007/s11295-017-1177-1

results). These rootstock effects were accounted in the model M1.

\subsection{Heterosis}

Growth traits (height and BHC) showed a clear bestparent heterosis (Fig 1, a-f) with the exception of BHC in $\mathrm{PC}$. In $\mathrm{SA}$, the best parental reference for growth traits was EL. In this site, at age 14, HL exceeded the best parental reference EL by $112.6 \mathrm{~cm}$ for height and $7.2 \mathrm{~cm}$ for BHC. Circumference contrasts evolved very slowly after age 14 . In SS, at age 18, EL and JL were not significantly different for growth traits; the contrast between HL and JL (respectively HL and EL) was $12.2 \mathrm{~cm}$ (respectively $17.3 \mathrm{~cm}$ ) for $\mathrm{BHC}$ and $185.5 \mathrm{~cm}$ (respectively $197.7 \mathrm{~cm}$ ) for height. Still in SS, growth traits contrasts showed a plateau after age 13. In both $\mathrm{SA}$ and $\mathrm{SS}$, heterosis for growth traits was highly significant $\left(p<10^{-3}\right)$ at the oldest age. In PC, the best parental reference for growth traits was JL. For trait BHC at age 11, JL significantly exceeded HL of $2.8 \mathrm{~cm}(p<0.05)$ and HL significantly exceeded EL of $13.0 \mathrm{~cm}\left(p<10^{-5}\right)$. Hybrid larch height exceeded both JL height of $55.6 \mathrm{~cm}(p<0.05)$ and EL height of $254.8 \mathrm{~cm}\left(p<10^{-5}\right)$.

Japanese larch was straighter (higher flexuosity score) than the hybrid in all sites and ages (Fig 1, j-1). This difference was significant at age 14 in SA (difference of $0.41, p<0.05$ ), at any age from age 4 in $\mathrm{SS}$ (maximum difference of $0.58, p<0.01$ ), and at age 3 in $\mathrm{PC}$ (difference of $0.43, p<0.01$ ). We also found a significantly higher straightness for EL than for HL in SS at age 4 (difference of $0.31, p<0.05$ ). Density pattern was consistent across sites: EL was the densest, JL the least dense, and HL was intermediate (Fig 1, $\mathrm{g}-\mathrm{i})$. These results were significant in SA $(p<0.01)$, in SS for JL vs. HL $\left(p<10^{-3}\right)$ and EL vs. HL at age 5 then from age 8 onwards $(p<0.01)$, and in PC only for JL vs. HL until age $8(p<0.05)$. There was no clear trend with age for density contrasts, except in $\mathrm{PC}$ where differences between taxa diminished with time.

Bud flush occurred slightly but significantly earlier for HL than for EL at age 12 in SS (difference of $0.39, p<0.001$ ) and later for HL than for JL at age 3 in SA (difference of $0.32, p<0.05$ ). The other differences between taxa for this trait were small and non-significant (results not shown). In the same way, we found no clear pattern for HWP but a few contrasts were significant: HL had a higher HWP than EL in $\mathrm{PC}(+7.16 \%, p<0.05)$ and than $\mathrm{JL}$ in $\mathrm{SA}(+3.55 \%$, $p<0.05)$; these were the highest contrasts for this trait.

In summary, best-parent heterosis was found in most sites for growth traits (HT and BHC). In PC, for $\mathrm{BHC}$, we only showed average-parent heterosis. Most of these heterotic advantages were attained at early ages (usually before 15), reaching a plateau in subsequent later ages. Hybrids looked intermediate for density, and poorer than the parental references for flexuosity.

\subsection{Heritabilities}

As previously detailed, genetic parameters were estimated in a Bayesian framework (no p-values and test of significance). We considered heritabilities lower than 0.2 as low, between 0.2 and 0.4 as moderate, and higher than 0.4 as high. European larch pure species heritabilities pattern strongly depended on the site (Fig 2, a-c). In SA, all EL heritabilities were moderate to high $\left(\hat{h}_{E}^{2} \in[0.232 ; 0.440]\right)\left(\hat{h}_{E}^{2}\right.$ : maximum a posteriori estimate for $\left.h_{E}^{2}\right)$; in SS only bud flush heritability was high $\left(\hat{h}_{E}^{2}=0.660\right)$, all the other heritabilities were low $\left(\hat{h}_{E}^{2} \leq 0.189\right)$; in PC heritability was high $\left(\hat{h}_{E}^{2}=0.471\right)$ for flexuosity and moderate for height and bud flush $\left(\hat{h}_{E}^{2}=0.288\right.$ and 0.310 respectively). On the contrary, JL pure species heritabilities pattern was better preserved across sites compared to EL (Fig 2, d-f). Indeed, for this taxon, flexuosity, bud flush and density heritabilities were high in SA and in SS $\left(\hat{h}_{J}^{2} \in[0.412 ; 0.609]\right)$ and intermediate in $\mathrm{PC}\left(\hat{h}_{J}^{2} \in[0.190 ; 0.532]\right)$; height heritabilities were low $\left(\hat{h}_{J}^{2} \in[0.151 ; 0.195]\right)$; and BHC and HWP heritabilities were very low $\left(\hat{h}_{J}^{2} \leq 0.094\right)$.

Hybrid heritability was high for bud flush $\left(\hat{h}_{H E}^{2}+\right.$ $\left.\hat{h}_{H J}^{2} \in[0.458 ; 0.651]\right)$ though parental contributions to hybrid heritability for this trait depended on the site: EL and JL contributions were almost equal in $\mathrm{SA}\left(\hat{h}_{H E}^{2}=0.330\right.$ and $\left.\hat{h}_{H J}^{2}=0.322\right)$ whereas EL parent contributed almost solely in $\mathrm{SS}\left(\hat{h}_{H E}^{2}=0.516\right.$ and $\left.\hat{h}_{H J}^{2}=0.135\right)$ (Fig 2, a-f). Hybrid heritability was moderate to high for flexuosity $\left(\hat{h}_{H E}^{2}+\hat{h}_{H J}^{2} \in\right.$ $[0.326 ; 0.546])$ with an important EL contribution in PC $\left(\hat{h}_{H E}^{2}=0.378\right)$. Hybrid total heritability was also moderate to high for density $\left(\hat{h}_{H E}^{2}+\hat{h}_{H J}^{2} \in[0.294 ; 0.502]\right)$, only due to JL contributions $\left(\hat{h}_{H J}^{2} \in[0.250 ; 0.410]\right)$ as EL contributions were negligible for this trait $\left(\hat{h}_{H E}^{2} \leq\right.$ 0.092). European larch contributed only a little to height in SA ( $\left.\hat{h}_{H E}^{2}=0.203\right)$ and in SS $\left(\hat{h}_{H E}^{2}=0.197\right)$. There was also a weak contribution from JL to HWP heritability in SS $\left(\hat{h}_{H J}^{2}=0.160\right)$. All other HL heritabilities (excluding young stage heritabilities in SS) were low (Fig 2, a-f).

Therefore, bud flush and flexuosity resulted in the highest heritabilities across sites and taxa. Density heritability was high for JL and was under JL control in hybridization. Growth traits and HWP attained generally the lowest levels of heritability. The ranking in heritabilities among traits was better preserved in 
Version définitive du manuscrit publié dans / Final version of the manuscript published in :

Tree Genetics \& Genomes, october 2017, https://doi.org/10.1007/s11295-017-1177-1
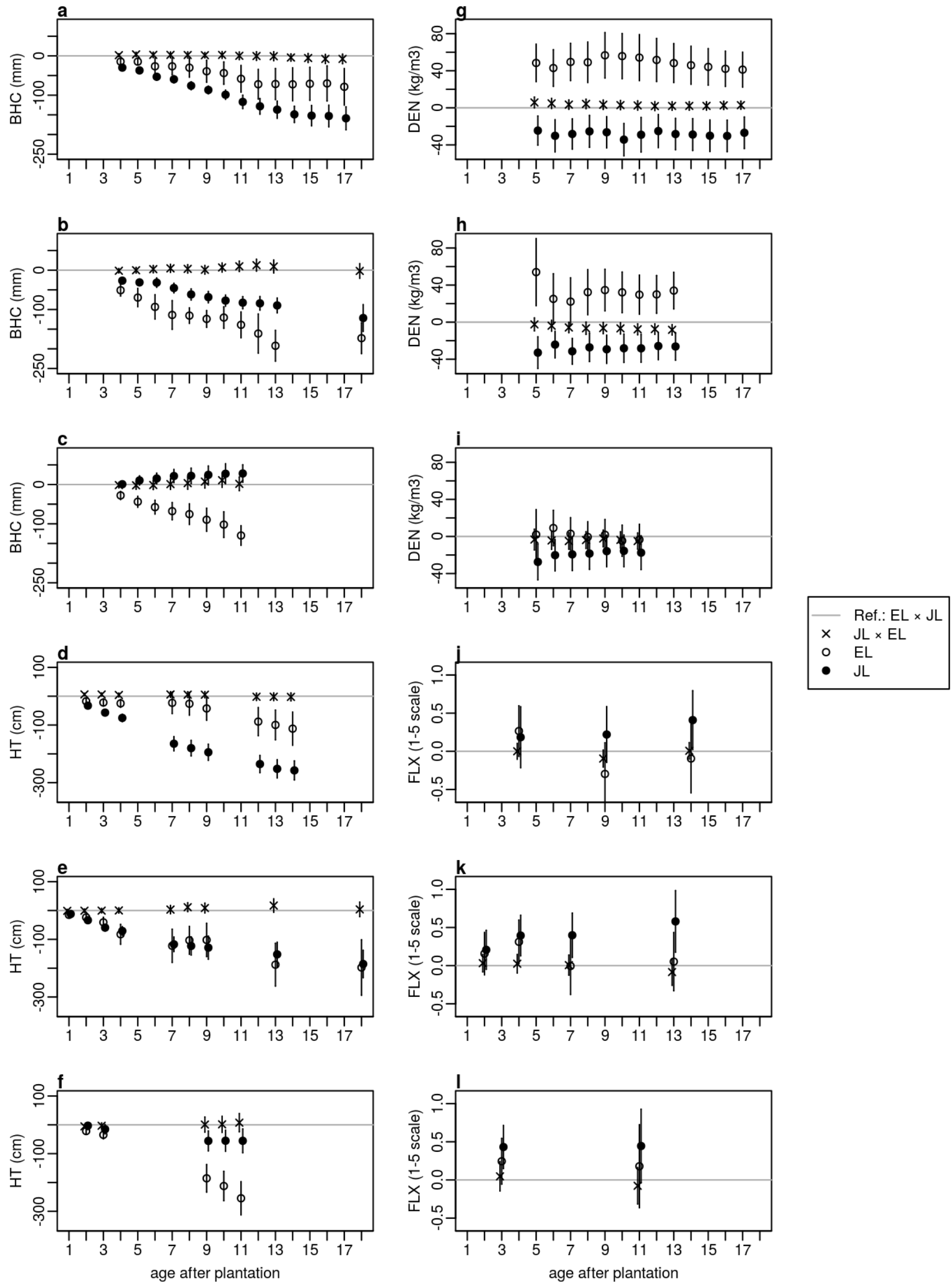

Figure 1: Contrasts between taxa means and European larch $\times$ Japanese larch $(\mathrm{EL} \times \mathrm{JL})$ means (horizontal bar: $y=0$ ), for breast-height circumference (BHC) (a-c), height (HT) (d-f), wood density (DEN) (g-i) and stem flexuosity (FLX) (j-l) over age, in Saint-Appolinaire (a, d, g, j), Saint-Saud (b, e, h, k) and Peyrat-leChâteau (c, f, i, l). White dot: EL; black dot: JL; $\Varangle$-shaped dot: reciprocal hybrid $(\mathrm{JL} \times \mathrm{EL})$. All vertical bars: $95 \%$ confidence intervals under normal distribution assumption 
Version définitive du manuscrit publié dans / Final version of the manuscript published in :

Tree Genetics \& Genomes, october 2017, https://doi.org/10.1007/s11295-017-1177-1

a

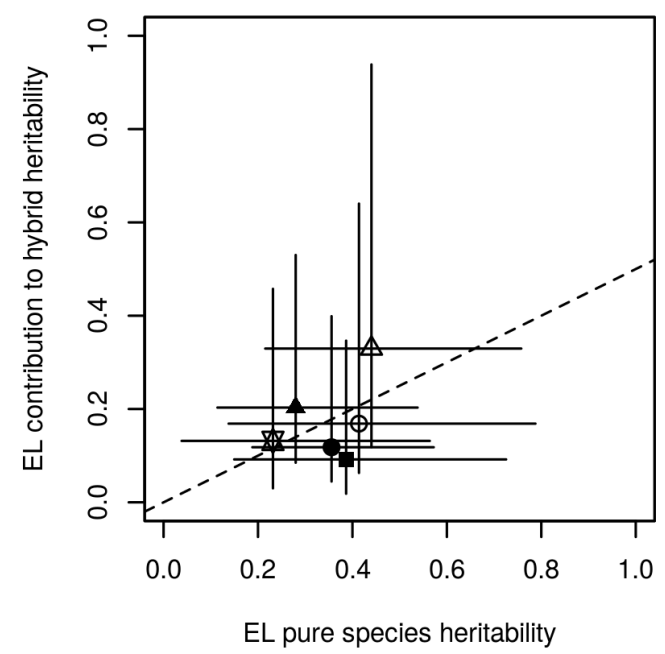

b

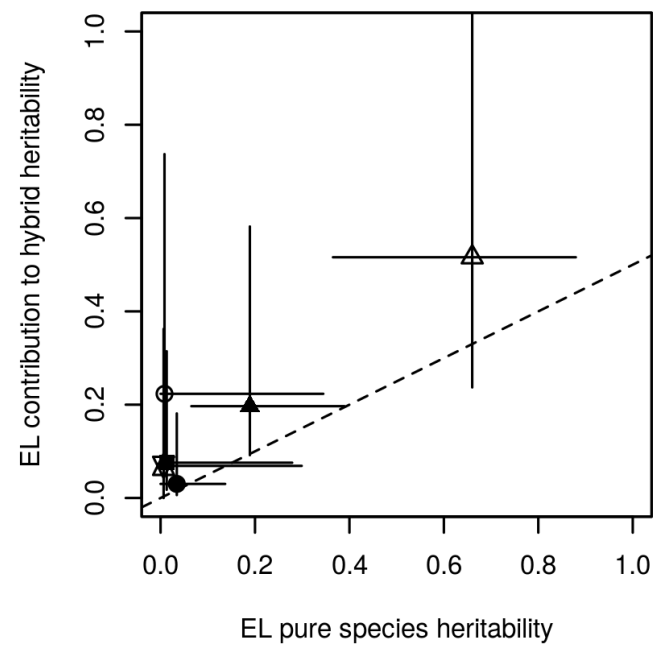

C

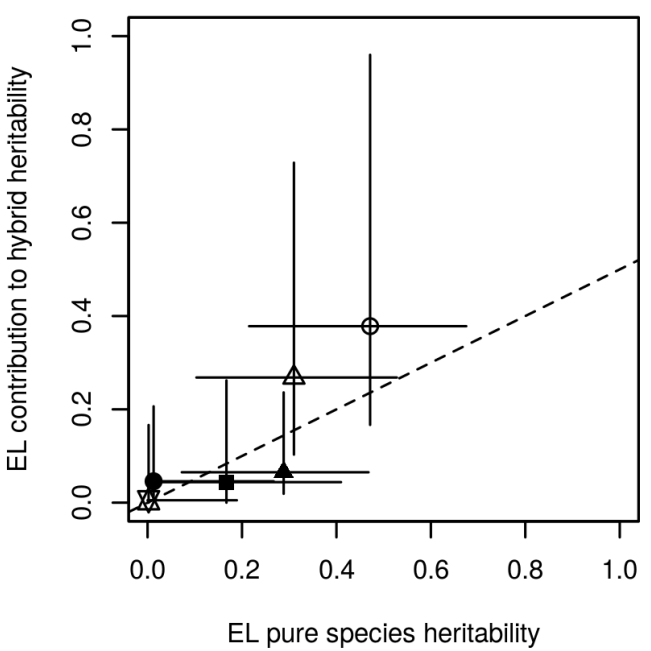

d

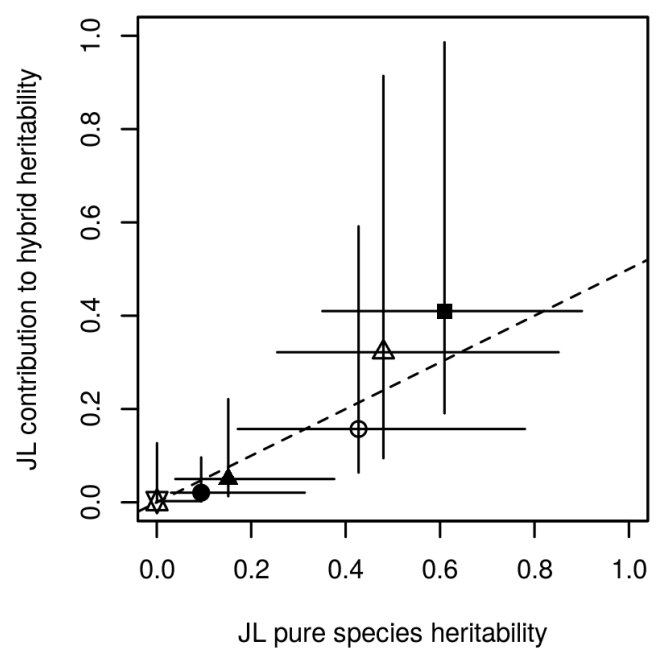

e

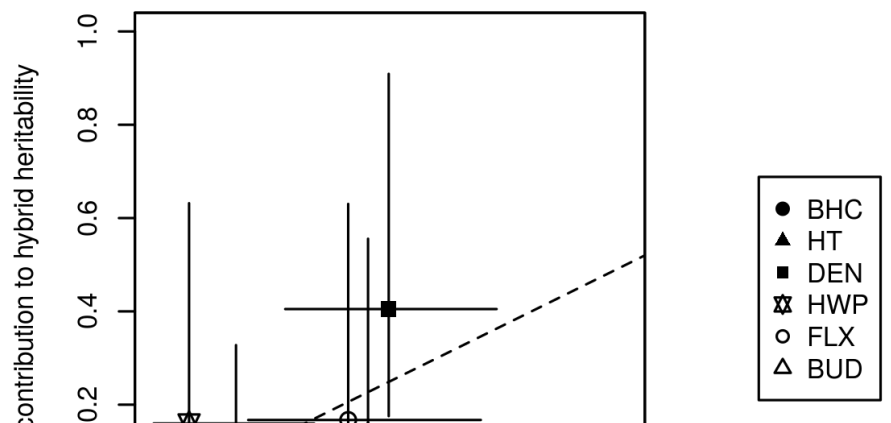

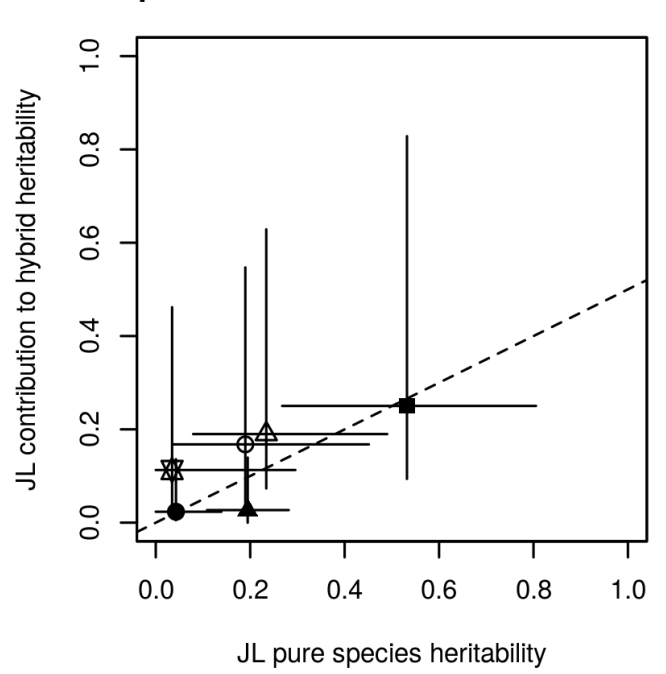

Figure 2: Pure species narrow-sense individual heritabilities vs. contributions to hybrid narrow-sense heritabilities, for European larch (a-c) and Japanese larch (d-f), in Saint-Appolinaire (a, d), Saint-Saud (b, e), and Peyrat-le-Château (c, f); for breast-height circumference (BHC), total height (HT), wood density (DEN), heartwood proportion (HWP), stem flexuosity (FLX) 10 bud flush (BUD). The legend is provided on the side. Horizontal and vertical lines: $95 \%$ CIs. $(\mathrm{y})=$ young stage. Dotted line: $y=\frac{1}{2} x$ 
Version définitive du manuscrit publié dans / Final version of the manuscript published in :

Tree Genetics \& Genomes, october 2017, https://doi.org/10.1007/s11295-017-1177-1

JL across sites compared to EL. In particular, EL heritabilities both in pure species and in hybridization were generally higher in SA than in the other sites, even for growth traits. In general, EL had higher contributions to hybrid heritabilities for flexuosity and bud flush than JL.

\subsection{Degrees of dominance}

Degrees of dominance were very low for all traits for all taxa at all sites (Appendix 2 Fig. 6). The highest degree of dominance we estimated was 0.136 for wood density of $\mathrm{HL}$ in $\mathrm{PC}$; any other degree of dominance was under 0.089 .

\subsection{Additive correlations}

Only a few additive genetic correlations CIs excluded 0 (Fig. 3), whereas a lot of residual correlations CIs were above or below 0 (Appendix 2, Fig. 7). Additive correlation between bud flush and flexuosity was negative across sites and taxa (ranging from -0.581 to -0.073), meaning the later the bud flush, the straighter was the stem. This correlation was markedly negative in $\mathrm{PC}$ for pure EL species, with most of the posterior distribution below $0\left(\hat{r}_{A E}=-0.396,95 \%\right.$ CI below 0 meaning $\left.P\left(r_{A E}>0\right)<2.5 \%\right)$ and similarly for pure JL species $\left(\hat{r}_{A J}=-0.380,90 \%\right.$ CI below 0 meaning $\left.P\left(r_{A J}>0\right)<5 \%\right)$. On the other hand, in SA, bud flush and $\mathrm{BHC}$ additive correlation was positive for EL pure species $\left(\hat{r}_{A E}=0.501, P\left(r_{A E}<0\right)<5 \%\right)$, meaning the earlier the bud flush, the larger was the stem.

In PC, additive correlation between height and density was positive for the pure EL and the pure JL species $\left(\hat{r}_{A E}=0.862, P\left(r_{A E}<0\right)<2.5 \%\right.$ and $\hat{r}_{A J}=$ $0.390, P\left(r_{A J}<0\right)<2.5 \%$ respectively $)$. In the same way, in SS, we found a positive additive correlation between height and density in the pure JL species $\left(\hat{r}_{A J}=0.514, P\left(r_{A J}<0\right)<5 \%\right)$. We also estimated positive additive correlations, though with some more uncertainty, between height and density for the pure EL species $\left(\hat{r}_{A E}=0.404\right)$ and both species contributions to hybridization $\left(\hat{r}_{H J}=0.356\right.$ and $\left.\hat{r}_{H E}=0.292\right)$. For JL in pure species as well as in hybridization, we always found negative additive correlation between BHC and density (ranging between -0.066 and -0.671). On the contrary, a positive correlation between BHC and density was found on the pure species EL side in $\mathrm{PC}\left(\hat{r}_{A E}=0.769, P\left(r_{A E}<0\right)<5 \%\right)$. Finally, additive correlation between $\mathrm{BHC}$ and height was positive for both pure species in SA $\left(\hat{r}_{A E}=0.712, P\left(r_{A E}<\right.\right.$ $0)<2.5 \%$ and $\left.\hat{r}_{A J}=0.484, P\left(r_{A J}<0\right)<5 \%\right)$; as well as in PC $\left(\hat{r}_{A E}=0.888, P\left(r_{A E}<0\right)<2.5 \%\right.$ and $\left.\hat{r}_{A J}=0.488, P\left(r_{A J}<0\right)<5 \%\right)$.

\subsection{Stability of performances in hybridiza- tion}

Stability (assessed as a Pearson correlation) between performances in pure species (BV) and in hybridization (GHA) showed a similar pattern to that of the heritability. For European larch, $r_{B V, G H A}$ were strongly site-dependent (Table 1). Indeed, for EL, $r_{B V, G H A}$ were moderate to high for all traits in SA, from 0.592 for height to 0.809 for HWP, 0.819 for flexuosity and 0.909 for bud flush. In PC, $r_{B V, G H A}$ was high for flexuosity (0.825) and for bud flush (0.722). Only bud flush had a high correlation in SS (0.801). For JL, still following the same trend as heritabilities, $r_{B V, G H A}$ were high for bud flush, flexuosity and density in any site (between 0.807 and 0.918 ), except for flexuosity in PC where $r_{B V, G H A}$ was only moderate (0.596). A graphical representation of performances correlations between BV and GHA, including performances CI, for bud flush, density and flexuosity is provided in Appendix 3, Fig 8-10. In short, BV appeared to be a good proxy of GHA for the highly heritable traits: bud flush and flexuosity, and density for JL. For the other less heritable traits, correlations were weak or, for EL, site-dependent.

\subsection{Stability of performances across sites}

Like the stability in hybridization, the stability of parents performances across sites (also assessed as Pearson correlations) were linked to the heritability of the traits; the most heritable traits were often the most stable across sites (Table 2). In pure species, EL showed high stability across sites for bud flush (between 0.763 and 0.918 ) only. However, the across-site stability of EL performance in hybridization was high for bud flush (between 0.894 and 0.911) and also for flexuosity (between 0.726 and 0.854 ), for HWP and for density in SA vs. SS (respectively 0.785 and 0.772 ), and for height in SS vs. PC (0.834). Following heritabilities trend, JL pure species performances were highly stable across sites for bud flush, flexuosity and density (between 0.687 and 0.955 ); across-site stability for height was also high in SS vs. PC (0.738). Across-site stabilities of JL performances in hybridization were high for density (between 0.817 and 0.899 ), but they showed a surprising pattern for flexuosity and bud flush: although they were high in SA vs. SS (respectively 0.927 and 0.923 ), they were only moderate in the comparisons involving PC (i.e. SA vs. PC and SS vs. PC) (between 0.643 and 0.681). Finally, JL across-site stability for height was moderate to high in hybridization in SA vs. SS (0.805) and SS vs. PC (0.672). A graphical representation of the across-site stability of the performances in hybridization is provided in Appendix 3, Fig. 11. 
Version définitive du manuscrit publié dans / Final version of the manuscript published in : Tree Genetics \& Genomes, october 2017, https://doi.org/10.1007/s11295-017-1177-1
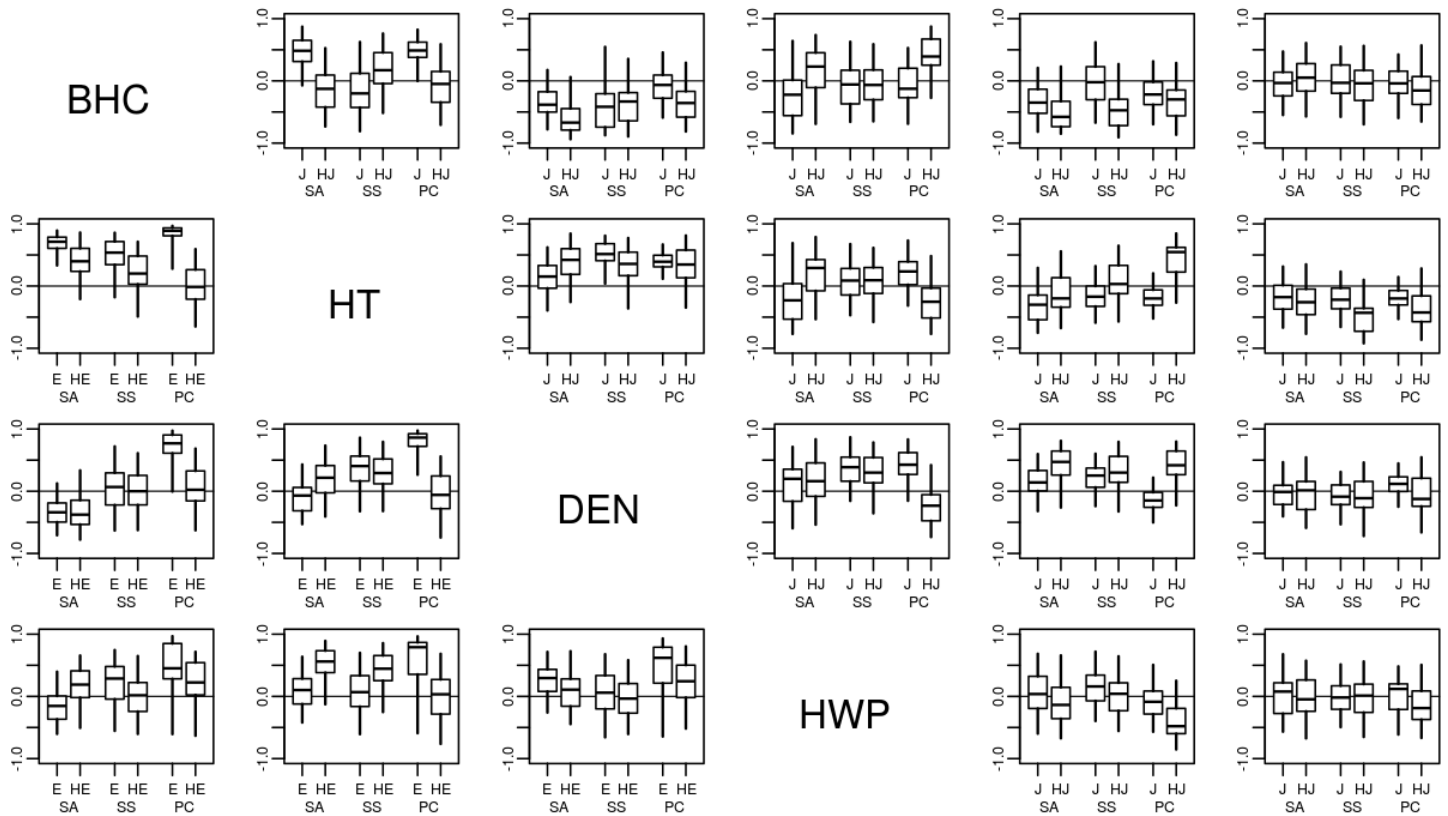

HWP
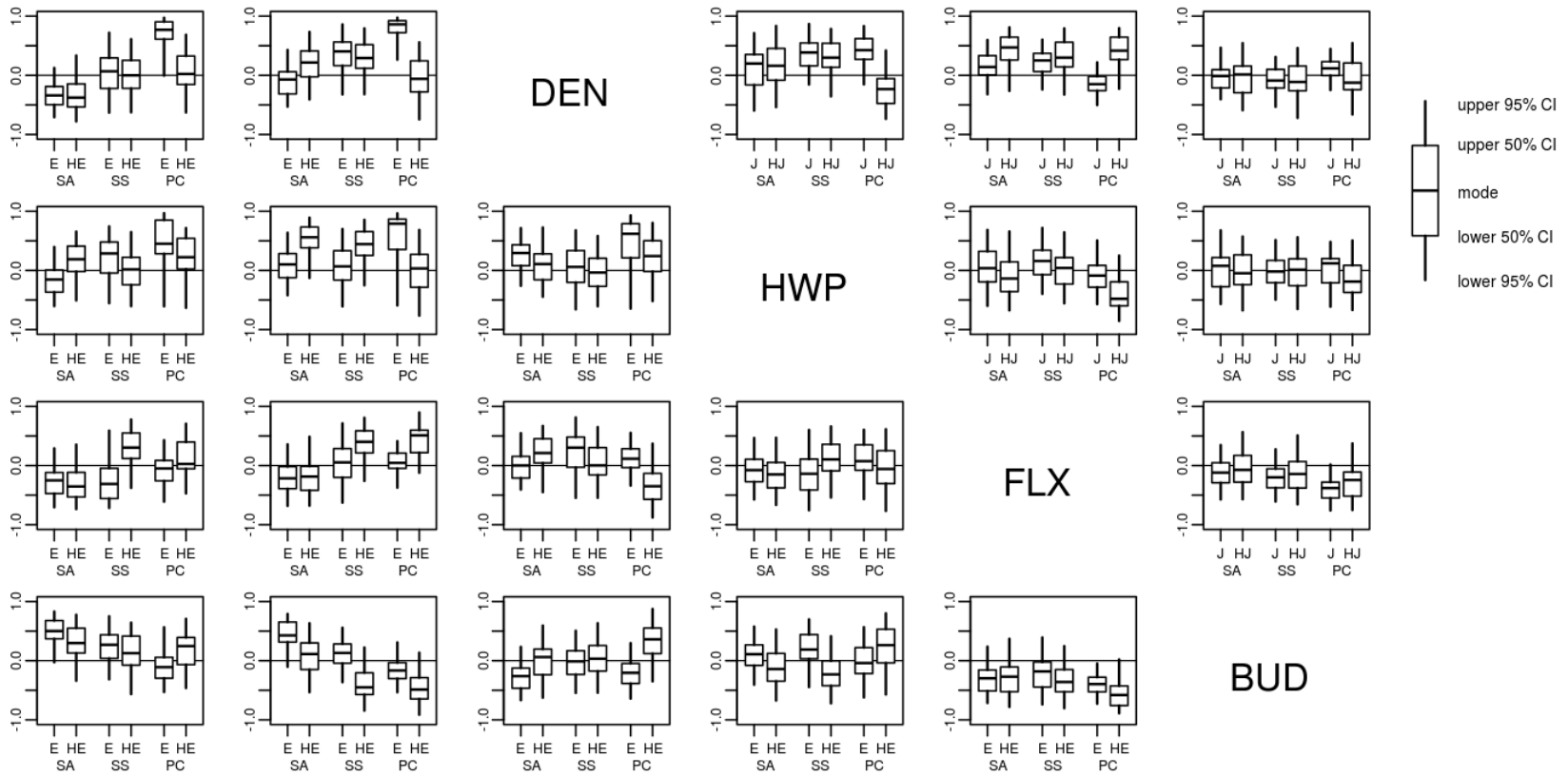

\section{BUD}

Figure 3: Additive genetic correlations between the traits: breast-height circumference (BHC), total height (HT), wood density (DEN), heartwood proportion (HWP), stem flexuosity (FLX), bud flush (BUD); on the European side (suffix 'E', bottom-left half-matrix) and on the Japanese side (suffix 'J', top-right half-matrix), in pure species (no prefix) or in hybridization (prefix 'H'); in each site: Saint- Appolinaire (SA), Saint-Saud (SS) and Peyrat-le-Château (PC). Whiskers: 95\% CIs; box: 50\% CIs; middle-line: mode (i.e. maximum a posteriori)

Briefly, JL showed more stable performances across sites than the EL counterpart for most of the assessed traits. Across-site correlations were particularly high in JL for highly heritable traits: bud flush, flexuosity and density. This trend of JL was paralleled in its contribution to hybrid performance across sites, with similar correlations and for the same set of stable traits. European larch, with less stable performances except for bud flush, showed a higher across-site stability in its contribution to the hybrid performances.

\section{Discussion}

Interspecific hybrids between European and Japanese larches present many desirable features in terms of growth and stability that are not observed simultaneously at parental level. Many hybrid varieties ex- ist, but hybrid larch as many other hybrids lacks to a large extent recurrent breeding efforts, notably by the absence of a formal breeding program. The first steps towards fulfilling this absence are the production of quantitative genetic knowledge on hybrid larch performance. Our study was based on one of the very few intra-/inter-specific diallel mating designs existing for forest trees.

Our study showed clear heterosis for growth traits (height and BHC). This advantage occurred already at a juvenile stage, with apparently little or no extra heterosis gained after age 15-16. Those traits that benefited the most from heterosis tended to show low to medium heritabilities, and were among those in the study being less stable across sites and with relatively low correlation between performances in pure and hybrid crosses. Heterosis over the best parent was absent from the traits showing the highest heritabilities 
Version définitive du manuscrit publié dans / Final version of the manuscript published in :

Tree Genetics \& Genomes, october 2017, https://doi.org/10.1007/s11295-017-1177-1

Table 1: Pearson correlations between performances in hybridization (GHA) and in pure species breeding (BV), in Saint Appolinaire (SA), Saint-Saud (SS) and Peyrat-le-Château (PC). EL vs. HL: comparison between European larch and hybrid larch and JL vs. HL: comparison between Japanese larch and hybrid larch. Exceedance probability: ': CI $(95 \%)$ above 0; *: CI $(95 \%)$ above $0.3{ }^{* *}$ : CI $(95 \%)$ above 0.6

\begin{tabular}{llll}
\hline site & trait & EL vs. HL & JL vs. HL \\
\hline SA & BHC & $0.654^{*}$ & 0.331 \\
& HT & $0.592^{\prime}$ & 0.475 \\
& DEN & $0.690^{*}$ & $0.870^{* *}$ \\
& HWP & $0.809^{*}$ & 0.151 \\
& FLX & $0.819^{*}$ & $0.807^{* *}$ \\
& BUD & $0.909^{* *}$ & $0.918^{* *}$ \\
SS & BHC & 0.271 & -0.028 \\
& HT & $0.452^{\prime}$ & $0.544^{\prime}$ \\
& DEN & 0.44 & $0.875^{* *}$ \\
& HWP & 0.397 & 0.475 \\
& FLX & 0.593 & $0.887^{* *}$ \\
PC & BUD & $0.801^{*}$ & $0.842^{* *}$ \\
& BHC & 0.026 & 0.362 \\
& HT & 0.201 & $0.453^{*}$ \\
& DEN & 0.547 & $0.911^{* *}$ \\
& HWP & 0.121 & -0.027 \\
& FLX & $0.825^{*}$ & 0.596 \\
& BUD & $0.722^{*}$ & $0.809^{*}$ \\
\hline
\end{tabular}

in the study, namely bud flush, stem flexuosity and wood density. These traits were stable across sites and showed generally high correlation between performances in pure and hybrid crosses. These results, although based on a relatively narrow base population, are of key importance when planning hybrid breeding for larch.

\subsection{Hybrid larch heterosis}

Best-parent heterosis in growth traits (BHC and total height) was validated in all sites, except in $\mathrm{PC}$ for $\mathrm{BHC}$ where HL almost reached its best parent (JL), though it overpassed it for height. As a result, regardless if the site was more favorable to EL or to JL, the hybrid yielded more than or as much as the best parent species for growth traits. For BHC, the relative best-parent global heterosis was $15.7 \%$ in SA (best parent: EL), the least 'fertile' site and $12.0 \%$ in SS (best parent: JL), the most 'fertile' site. In PC (similar 'fertility' as SS), the hybrid BHC was $6.3 \%$ lower than that of JL and $25.8 \%$ higher than that of EL (Fig. 1 and Appendix 2, Table 9). Using the multi-site diallel mating design trial we described here (though, including Cumière site instead of $\mathrm{PC}$ ), heterosis was already shown for growth traits at a juve-
Table 2: Pearson correlations between performances in the 3 sites: Saint Appolinaire (SA), Saint-Saud (SS) and Peyrat-le-Château (PC). Performances in pure species: 'EL' and 'JL'; Performances in hybridization: 'HE' and 'HJ' respectively. Exceedance probability: ': CI $(95 \%)$ above 0 ; *: CI $(95 \%)$ above $0.3{ }^{* *}$ : CI $(95 \%)$ above 0.6

\begin{tabular}{lllll}
\hline taxon & trait & SA vs. SS & SA vs. PC & SS vs. PC \\
\hline EL & BHC & 0.577 & 0.471 & 0.317 \\
& HT & $0.614^{\prime}$ & 0.489 & $0.477^{\prime}$ \\
& DEN & 0.359 & 0.529 & 0.183 \\
& HWP & 0.381 & 0.195 & 0.15 \\
& FLX & 0.719 & $0.684^{\prime}$ & 0.673 \\
& BUD & $0.918^{* *}$ & $0.829^{*}$ & $0.763^{*}$ \\
HE & BHC & 0.114 & 0.142 & $0.630^{\prime}$ \\
& HT & $0.534^{*}$ & $0.424^{\prime}$ & $0.834^{* *}$ \\
& DEN & $0.772^{*}$ & 0.514 & 0.457 \\
& HWP & $0.785^{*}$ & 0.344 & 0.142 \\
& FLX & $0.854^{* *}$ & $0.726^{*}$ & $0.836^{* *}$ \\
JL & BUD & $0.910^{* *}$ & $0.911^{* *}$ & $0.894^{* *}$ \\
& BHC & 0.263 & 0.314 & 0.372 \\
& HT & $0.682^{*}$ & $0.567^{*}$ & $0.738^{*}$ \\
& DEN & $0.955^{* *}$ & $0.926^{* *}$ & $0.911^{* *}$ \\
& HWP & 0.43 & 0.057 & 0.346 \\
& FLX & $0.912^{* *}$ & $0.687^{*}$ & $0.759^{*}$ \\
& BUD & $0.895^{* *}$ & $0.802^{*}$ & $0.844^{* *}$ \\
HJ & BHC & 0.55 & $0.639^{\prime}$ & 0.396 \\
& HT & $0.805^{*}$ & $0.536^{*}$ & $0.672^{*}$ \\
& DEN & $0.899^{* *}$ & $0.818^{* *}$ & $0.817^{* *}$ \\
& HWP & 0.559 & 0.436 & $0.454^{*}$ \\
& FLX & $0.927^{* *}$ & $0.669^{*}$ & $0.661^{*}$ \\
& BUD & $0.923^{* *}$ & $0.643^{*}$ & $0.681^{*}$ \\
\hline
\end{tabular}

nile stage (age 6) (Pâques, 2002). Near-rotation age (at year 22) heterosis between EL and JL has also been shown using a diallel mating design trial, in a single site in Central Maine, USA (Greenwood et al. 2015). Like us, Greenwood et al (2015) found no reciprocal effect between $\mathrm{JL} \times \mathrm{EL}$ and $\mathrm{EL} \times \mathrm{JL}$, and they demonstrated best-parent heterosis at the taxon level for height, BHC and volume over proper parental references. The novelty of our study was to show heterosis at near-rotation age in several contrasted sites, using a constant genetic material.

In SA and in SS, after age 15-16, hybrid superiority over its parental species reached a plateau for growth traits and more clearly for BHC. In SS only, the last thinning campaign could play a role in this phenomenon. Nevertheless, this result comforts the hypothesis that heterosis would be expressed at a juvenile stage, and that the acquired superiority would be conserved along the tree's life. Indeed, it is now well-known by foresters that hybrid larch in pure plantations reaches its maximum mean annual increment 
Version définitive du manuscrit publié dans / Final version of the manuscript published in : Tree Genetics \& Genomes, october 2017, https://doi.org/10.1007/s11295-017-1177-1

for stem volume 5 to 20 years earlier than its parental species (Rondeux, 2003). Also, in trials where taxa are closely inter-mixed as in our study, one can expect that hybrid with its rapid growth could have overgrown its parental counterparts in the neighborhood and prevented them from catching up at later ages. As an illustration, a link between genetic performances and competitiveness has been shown by Cappa et al (2015) in loblolly pine, with a high correlation (CI: 0.77 to 0.92 ) between BHC breeding value and competition ability. We failed to fit such a competition model (Muir, 2005; Muñoz and Sánchez, 2015) to our data. The model led to unreliable results, likely due to the mix of species and the over-parametrization, and it was thereby disregarded (result not shown). Presumably, competition could have interfered with the phenomenon of heterosis for growth traits, notably for $\mathrm{BHC}$ which is known to be affected by competition.

We did not find a clear pattern of best-parent heterosis for the other investigated traits. Hybrid wood density was intermediate between both parental values; this trend was clear and significant in SA and SS but more confused in PC. Similar results for hybrid wood density were also found in Pinus hybrids (Dungey, 2001). In larch, Charron et al (2003) already reported a lower hybrid wood density when compared to EL counterparts. Nevertheless, the fact that faster growing HL still produced higher density than its worst parent for this trait $(\mathrm{JL})$ is promising for further breeding and for the sustainability of larch wood products quality. Concerning the other traits, hybrid seemed to be less straight than its parents, notably when compared against JL. For bud flush and HWP, the ranking of taxa was not conclusive (result not shown).

Some singularities affected PC site, namely the absence of best-parent heterosis for $\mathrm{BHC}$, and the confusion of density ranking that was otherwise clear in the other sites. Given that PC was the only site with grafted trees, one can suspect complex interactions between rootstocks and scions to be one of the underlying causes of this singularity. Rootstock species effects were found for growth traits (Appendix 2, Fig. 5 ). This finding indicates that the use of grafted trees may introduce an additional unwanted source of variation that should be taken into account in any case. On the other hand, we showed for growth traits that any species grafted on a hybrid rootstock may express some heterosis that led to a gain in height and in BHC after 11 years. This finding suggests thus that heterosis results not only from favorable functional properties of the aerial part but also from the below-ground part of the tree.

\subsection{Heritabilities}

Some traits showed high heritabilities: bud flush, stem flexuosity and, for JL only, wood density. The gain in selection relies on high heritabilities as well as on phenotypic variances (Falconer and Mackay, 1996). Across sites and taxa, the estimated phenotypic standard deviations ranged from 0.79 to 1.22 for flexuosity on the 1-5 scale; from 0.66 to 1.18 for bud flush on the 0-6 scale (Appendix 2, Table 9). Therefore, it is possible to improve these traits through breeding. However, wood density standard deviation was quite low (ranging from 28.6 to $42.0 \mathrm{~kg} \cdot \mathrm{m}^{-3}$ ) so the perspectives of gain for this trait remain low.

For all taxa, height heritability was often intermediate, and for BHC and HWP, heritabilities were mostly low. The general trend was not perfectly followed by EL however, showing a site-conditional expression of its heritabilities. In particular, $\mathrm{BHC}$ heritability was moderate for EL in SA $\left(\hat{h}_{E}^{2}=0.356\right)$ and accompanied by a phenotypic standard deviation of $101.9 \mathrm{~mm}$. We also found a very low EL heritability for stem flexuosity in SS. This may be explained by the thinning that occurred in this site. Indeed, thinning censure could not be recovered from young stage observations because of the quite low additive correlation between young and old stage flexuosity for EL in SS $\left(\hat{r}_{A E}=0.455\right)$. On the other hand, JL heritabilities were generally better preserved across sites, with high magnitudes for density, bud flush and flexuosity. Interestingly, considering all taxa, the most heterotic traits (BHC and height) were associated with low to moderate heritabilities, whereas non-heterotic traits such as bud flush, stem flexuosity and wood density were highly heritable. This suggests that biomass related traits (BHC and height) could mostly be improved at the hybridization stage, whereas bud flush, density and flexuosity could be improved by recurrent selection within the pure species. Indeed, these later traits showed generally high stability of the performances in hybridization. Hybrid wood density was clearly under JL additive control. Only HWP showed a difficult path towards genetic improvement, with no heterosis and a very low level of heritability. However, as absolute heartwood size follows stem size (Pâques and Charpentier, 2015), total heartwood size may be improved along with BHC through hybridization.

We compared our narrow-sense heritabilities estimates (Fig. 2) to the ones from the literature which were reviewed by Pâques (2013) (Appendix 4, Fig. 12). Only EL and HL heritabilities were available for a few traits in this review. The EL heritabilities (h2E) that we estimated were well within the range of variation of the other authors' estimates for bud flush, height and flexuosity, except for flexuosity in SS for which our estimation was noticeably low. On 
Version définitive du manuscrit publié dans / Final version of the manuscript published in :

Tree Genetics \& Genomes, october 2017, https://doi.org/10.1007/s11295-017-1177-1

the other hand, BHC heritabilities were lower than the ones found in the literature, except in SA where it was consistent with published values. Hybrid heritabilities $\left(h_{H E}^{2}+h_{H J}^{2}\right)$ were close to the literature references for flexuosity and density, but our study obtained lower estimates for height and BHC than those already published. Only Hering (1990, in Pâques, 2013) found also low heritabilities for these growth traits. More generally, moderate heritabilities for height and high ones for wood density could be expected for tree species (e.g. see Cornelius, 1994; Kain, 2003), but according to these studies our estimated flexuosity heritabilities were unusually high and the BHC ones were unusually low.

Heritability underestimation, notably for growth traits, could be due to the inter-specific competition in our experimental design. Indeed, a potential limitation of our study came from our single- (or in PC three-) tree plot design, which may have enhanced competition between taxa. Some authors found a link between competition and depletion of heritability. Lin et al (2013) showed a depletion on breast-height diameter heritability at age 5 in Pinus radiata under competition induced by a high plantation density. Also at high plantation density, Bouvet et al (2003) observed a depletion of both BHC and height heritabilities in $E u$ calyptus hybrids. Although this latter depletion was not significant, this effect remained stable from age 4 onwards and it was validated in 3 independent trials. The question remains nevertheless on how far interspecies vs. intra-species competition affects heritability estimates.

Some of our results had no correspondence to those in Pâques (2004). The wood density, which we found mostly under Japanese larch control, was estimated to be under European larch control by Pâques (2004). Unlike this latter publication, we found little heritability for growth traits (height and BHC), and stem flexuosity being under European or both parents control. Several reasons may contribute to explain this. On one hand, our findings highlight the need to assess these parameters in several environments, while Pâques (2004) results come from a single site, which was different from ours. On the second hand, the mating design was more unbalanced in Pâques (2004) and included different genetic basis with EL from the Alps.

Pâques and Charpentier (2015) found HL HWP heritability (full-sib family mean $h^{2}$ ) to be lower (0.49) than heartwood diameter heritability (0.68), but still higher than our narrow-sense heritability estimates $\left(\hat{h}_{E}^{2}\right.$ $\hat{h}_{J}^{2}$ and $\hat{h}_{H E}^{2}+\hat{h}_{H J}^{2}$ ranging between near 0 and 0.232 ). This could suggest that for this trait there was either little genetic variance in our sampling, or lack of accuracy in our measurement method.

\subsection{Dominance}

The dominance variances and the subsequent degrees of dominance we estimated were very low $\left(\hat{d}^{2} \leq 0.136\right)$, even for traits showing heterosis. Kain (2003) also found very low $d^{2}$ (between 0 and 0.1 ) for 17 traits in the 2 Pinus pure species he investigated, however he obtained high dominance to additive variance ratio in Pinus elliottii var. elliottii $\times$ Pinus caribaea var. hondurensis hybrid for some traits including breast height diameter and volume. Dungey (2001) pinpointed that in several species the relative importance of dominance variance tends to diminish with age. This trend was also found in hybrid larch (Pâques, 1992a). In the present article, we presented the analysis of data collected on old trees, generally older than in many of the reviewed articles in Pâques (2013), which overall leads to particularly reliable estimations of the additive genetic performances.

\subsection{Additive correlations}

Bud flush was genetically correlated with flexuosity. We found a negative additive correlation between these two traits, meaning the later the bud flush, the straighter the stem was. We also found a positive additive correlation between bud flush and $\mathrm{BHC}$ in SA, pinpointing to the need for a trade-off between BHC and flexuosity if selecting on bud flush. We also showed positive additive genetic correlation between height and density in SS and in PC. This could be an effect of the competition within these 2 sites. Indeed, though regularly thinned, SS is from far the most fertile site, and PC is also more fertile than SA (see Appendix 1, Table 6, and taxa means ranking in Appendix 2, Table 9). Therefore we could expect competition to be stronger in SS and PC than in the somehow poorer SA site. However, the hypothesis that competition leads to positive correlations between height and density would deserve further investigation. Wood density variability was under JL control, and for this taxon we found a negative correlation between density and $\mathrm{BHC}$, in pure species as well as in hybridization. This trend was only supported by moderate statistical evidence in hybridization in SA; but it might pinpoint at the possible trade-off between wood volume and wood quality, an issue raised by Kain (2003) with hybrid pines. However, on one hand, gain in wood productivity using best-parent heterosis at the taxon scale was not accompanied by a loss of density, as hybrid density was intermediate between its parental species. On the other hand, based on heritability differences alone, a genetic improvement of wood density would be more effective than that of wood volume. 


\subsection{Stability of performances}

Correlations between BV and GHA and across-sites correlations followed the same pattern as heritabilities. This could be expected as low heritability traits lack the genetic information that is needed to properly assess these correlations. Conversely, we found high correlations between BV and GHA for high heritability traits. This result was in line with Dieters and Dungey (2000)'s suggestion that the correlation between $\mathrm{BV}$ and $\mathrm{GHA}$ may be positively related to additive to dominance variance ratio, as we found very low $d^{2}$ and $\frac{h^{2}}{d^{2}}=\frac{\sigma_{A}^{2} / \sigma_{P}^{2}}{\sigma_{D}^{2} / \sigma_{P}^{2}}=\frac{\sigma_{A}^{2}}{\sigma_{D}^{2}}$. Correlations between $\mathrm{BV}$ and GHA and across-site correlations are both valuable parameters for guiding the choice of breeding strategies. On one hand, the high correlations between pure species and hybrid performances indicate that breeding efforts at the parental species level can be easily translated into comparable progress at the hybrid stage. On the other hand, we expect the genetic gains to be stable across sites, especially for flexuosity and bud flush in hybridization. Moreover, the high proportionality between JL density performances in pure species and in hybridization together with the stability of JL density performances across sites are very valuable; they allow a field screening of JL trees for their genetic value for this trait in hybridization.

\subsection{About the method}

The MCMC algorithms used in this study are rarely used in quantitative genetic studies of forest tree species. However, these algorithms present many computational advantages. Overall, they tend to be robust solvers even when low level of genetic information is available. Using PX prior, we could handle close-to-zero variances, an issue sometimes met with average-information REML algorithm (e.g. see Mutete et al, 2015). The prior parametrization we used was flexible enough for variances as well as for covariances components. Heritabilities estimates ranged from almost 0 to 0.660 , showing that phenotypic variance could be properly partitioned according to data information. In the same way, correlations estimates ranged between close-tozero and close-to-one (plus or minus one, $\max \left(\left|\hat{r}_{A}\right|\right)=$ 0.888 and $\left.\max \left(\left|\hat{r}_{R}\right|\right)=0.895\right)$; for the PX (genetic) posteriors (Fig. 3) as well as for the improper (residual) posteriors (Appendix 2, Fig. 7). The possibility to make direct inference on derived parameters such as heritabilities and genetic correlations was very powerful. We could also measure the reliability of our correlations between $\mathrm{BV}$ and $\mathrm{GHA}$, an issue raised by Dungey (2001).

In order to get rid from the inter-taxa competition interference, it could be interesting to re-think our experimental design for further study of such contrasted taxa. Pure taxa micro-plot design might be an alternative solution. However, border trees would still be exposed to inter-taxa competition, so they would have to be excluded - raising an extra-cost. Moreover, the spatial effect would be in confusion with the taxon effect. Spatial analysis methods that are less susceptible to high frequency effects, such as splines (Muñoz and Sánchez, 2015), could be a solution for the analysis of such an experimental design. Another solution would be the use of large pure taxa macroplot design. However, taxa and environment effects would be confounded; using clonal repetitions as control in each macro-plot would produce an extra-cost because of border trees; and an extra-difficulty because of the potential interactions between the genetic material and the environment.

\subsection{Conclusion}

Hybrid outperformed, or at least equaled, both of its parents and this occurred in all three testing sites, without degrading wood density, one key wood property. This highlights the interest to develop in priority hybrid larch varieties. Although our results here are based on a relatively small sample of parents from both species, we could layout the broad outlines of a strategy for hybrid larch breeding. Basically, traits felt into two contrasting behaviors: those showing relatively high heritabilities, high across-site stabilities and high stabilities of performances in hybridization, and those with relatively low heritabilities, low acrosssite stabilities and low stabilities of performances in hybridization. The former group included bud flush, stem flexuosity and wood density, which could be easily improved by selection at the parental stage and be evaluated interchangeably by the mean of inter- or intra-specific progeny tests. The prospects for improving straightness at the parental level could somehow compensate the medium to poor performances of the hybrid for this trait in comparison to its parents. The additive correlation between bud flush and flexuosity would facilitate the selection on these 2 traits simultaneously. Hybrid larch wood density was intermediate between its parents, but it can be improved by selection on the JL side. Hybrids in a reciprocal recurrent selection could recover improvement made at the parental stage for these traits. Growth traits quantitative genetics was shown to be more complex, resulting in less heritable patterns and presumably with phenotypic expressions prone to be affected by interspecific competition. However, these traits were also the ones benefiting the most from hybridization. The fact that growth traits in our study presented performances that were site dependent could indicate the need for strategies where selection is tailored depending on hybrid deployment. In that sense, our study 
Version définitive du manuscrit publié dans / Final version of the manuscript published in :

Tree Genetics \& Genomes, october 2017, https://doi.org/10.1007/s11295-017-1177-1

further supports the hypothesis of hybrid gaining site stability with respect to its parents, which is valuable in the handling of $\mathrm{G} \times \mathrm{E}$ and in the context of current environmental instability.

\section{Acknowledgement}

The authors sincerely acknowledge staff of INRA experimental units (UE GBFOR and UE BIOGECO) who have established, maintained and assessed the field trials as well as collected the increments cores. The authors thank Genobois platform technical staff who have prepared and X-rayed wood samples and provided microdensitometry profiles. Thanks also to Jarrod Hadfield for his kind help with the package MCMCglmm, and Pierre de Villemereuil, Luis Varona and Sebastián Munilla for their advices with Bayesian statistics. F. Muñoz was partially funded by research grant MTM2013-42323-P from the Spanish Ministry of Economy and Competitiveness and ACOMP/2015/202 from Generalitat Valenciana (Spain). F. Muñoz and L. Sánchez received funding from the European UnionâĂŹs Seventh Framework Program for research, technological development, and demonstration under grant agreement no. 284181 ('Trees4Future'). The authors also thank two anonymous reviewers and an associate editor for their comments and suggestions.

\section{Compliance with Ethical Standards}

\section{Conflict of interest}

The authors declare that they have no conflict of interest.

\section{Data Archiving Statement}

Our datasets are being submitted to GnpIS INRA Repository and the accession numbers will be supplied once available. We acknowledge that the final acceptance of a manuscript into TGG is contingent on all relevant accession numbers being made available in text.

\section{References}

Baltunis BS, Greenwood MS, Eysteinsson T (1998) Hybrid vigor in Larix: growth of intra-and interspecific hybrids of Larix decidua, L. laricina, and $L$. kaempferi after 5-years. Silvae Genetica 47(5):288293

Baranwal VK, Mikkilineni V, Zehr UB, Tyagi AK, Kapoor S (2012) Heterosis: emerging ideas about hybrid vigour. Journal of Experimental Botany 63(18):6309-6314
Bouvet JM, Vigneron P, Gouma R, Saya A (2003) Trends in variances and heritabilities with age for growth traits in eucalyptus spacing experiments. Silvae Genetica 52(3-4):121-133

Cappa EP, Muñoz F, Sánchez L, Cantet RJC (2015) A novel individual-tree mixed model to account for competition and environmental heterogeneity: a Bayesian approach. Tree Genetics \& Genomes 11(6):120

Charron S, Jourez B, Marchal M, Hébert J (2003) Etude comparative des caractéristiques physiques et mécaniques du bois des mélèzes d'Europe (Larix decidua Mill.), du Japon (Larix kaempferi (Lambert) Carr.) et de leur hybride (Larix $\tilde{A} U^{\circ}$ eurolepis Henry). Biotechnologie, Agronomie, Société et Environnement 7(1):5-16, URL http://orbi . $\mathrm{ulg}$. be/handle/2268/20732

Chen ZJ (2013) Genomic and epigenetic insights into the molecular bases of heterosis. Nature Reviews Genetics 14(7):471-482

Cornelius J (1994) Heritabilities and additive genetic coefficients of variation in forest trees. Canadian Journal of Forest Research 24:372-379

Cros D (2014) Etude des facteurs contr Ãttlant lâĂŹefficacité de la sélection génomique chez le palmier Āă huile (Elaeis guineensis Jacq.). Dissertation, Montpellier SupAgro

Dieters MJ, Dungey HS (2000) Relationship between the relative importance of non-additive variance and the genetic correlation between hybrid and parental populations in some Pinus species. In: Dungey HS, Dieters MJ, Nikles DG (eds) Hybrid breeding and genetics of forest trees proceedings of QFRI/CRCSPF symposium, 9-14th April 2000, Noosa, Queensland, Australia. Department of Primary Industries (Brisbane), pp 87-92

Dungey HS (2001) Pine hybrids - a review of their use performance and genetics. Forest Ecology and Management 148(1-3):243-258, DOI 10.1016/ S0378-1127(00)00539-9

Falconer DS, Mackay TF (1996) Introduction to quantitative genetics, 4 th edn. Longman, Harlow

Gallais A (2009) Hétérosis et variétés hybrides en amélioration des plantes. Quae, Versailles

Gauchat M, Pâques LE (2011) Indirect prediction of bud flushing from ex situ observation in hybrid larch (Larix decidua $\tilde{A} U^{\circ}$ L. kaempferi) and their parents. Environmental and Experimental Botany 70(2-3):121-130, DOI 10.1016/j.envexpbot. 2010.08.001, URL http://linkinghub.elsevier. com/retrieve/pii/S009884721000153X 
Version définitive du manuscrit publié dans / Final version of the manuscript published in : Tree Genetics \& Genomes, october 2017, https://doi.org/10.1007/s11295-017-1177-1

Gelman A (2006) Prior distributions for variance parameters in hierarchical models (comment on article by Browne and Draper). Bayesian Analysis 1(3):515-534, URL http://projecteuclid.org/ euclid.ba/1340371048

Gelman A, Hill J (2007) Data analysis using regression and multilevel/hierarchical models. Cambridge University Press, New York

Gianola D, Im S, Macedo F (1989) A framework for prediction of breeding value. In: Gianola D, Hammond K (eds) Advances in Statistical Methods for Genetic Improvement of Livestock, Springer-Verlag, Berlin, pp 210-238

Greenwood MS, Roth BE, Maass D, Irland LC (2015) Near rotation-length performance of selected hybrid larch in central maine, usa. Silvae Genetica 64(12):73-80

Hadfield J (2010) MCMC methods for multi-response generalized linear mixed models: the MCMCglmm $\mathrm{R}$ package. Journal of Statistical Software 33(2):122

Hinkelmann K (1974) Two-level diallel cross experiments. Silvae Genetica 23(1-3):18-22

Kain DP (2003) Genetic parameters and improvement strategies for the Pinus elliottii var. elliottii ÂU $P i$ nus caribaea var. hondurensis hybrid in Queensland, Australia. Dissertation, Australian National University

Kearsey MJ, Pooni HS (1996) The genetical analysis of quantitative traits. Chapman \& Hall, London

Keiding H, Olsen HC (1965) Assessment of stem form in clones and progenies of larch. Silvae Genetica 14(4):115-122

Knight R (1973) The relation between hybrid vigour and genotype-environment interactions. Theoretical and Applied Genetics 43(7):311-318

Li B, Wu R (1996) Genetic causes of heterosis in juvenile aspen: a quantitative comparison across intraand inter-specific hybrids. Theoretical and Applied Genetics 93(3):380-391

Li B, Wu R (1997) Heterosis and genotype $\tilde{\mathrm{A}} \mathrm{U}$ environment interactions of juvenile aspens in two contrasting sites. Canadian Journal of Forest Research 27(10):1525-1537, URL http : //www . nrcresearchpress . com/doi/pdf/ 10.1139/97-110

Li B, Wyckoff GW, Einspahr DW (1993) Hybrid aspen performance and genetic gains. Northern Journal of Applied Forestry 10(3):117-122
Lin Y, Yang H, Ivkovi $\breve{A} \breve{G}$ M, Gapare WJ, Matheson AC, Wu HX (2013) Effect of genotype by spacing interaction on radiata pine genetic parameters for height and diameter growth. Forest Ecology and Management 304:204-211

Liu C, Rubin DB, Wu YN (1998) Parameter expansion to accelerate EM: The PX-EM algorithm. Biometrika 85(4):755-770

Lo LL, Fernando RL, Grossman M (1997) Genetic evaluation by BLUP in two-breed terminal crossbreeding systems under dominance. Journal of animal science $75(11): 2877-2884$

Marchal A, Legarra A, Tisné S, Carasco-Lacombe C, Manez A, Suryana E, Omoré A, Nouy B, DurandGasselin T, Sánchez L, Bouvet JM, Cros D (2016) Multivariate genomic model improves analysis of oil palm (Elaeis guineensis Jacq.) progeny tests. Molecular Breeding 36:2, DOI 10.1007/s11032-015-0423-1

Muñoz F, Sánchez L (2015) breedR: statistical methods for forest genetic resources analysts. URL https://github.com/famuvie/breedR, r package

Muir WM (2005) Incorporation of competitive effects in forest tree or animal breeding programs. Genetics 170(3):1247-1259, DOI 10.1534/genetics. 104.035956, URL http://www.genetics.org/cgi/ doi/10.1534/genetics.104.035956

Mutete P, Murepa R, Gapare WJ (2015) Genetic parameters in subtropical pine F1 hybrids: heritabilities, between-trait correlations and genotype-byenvironment interactions. Tree Genetics \& Genomes 11:93, DOI 10.1007/s11295-015-0926-2

Nikles DG, Griffin AR (1991) Breeding hybrids of forest trees: definitions, theory, some practical examples, and guidelines on strategy with tropical acacias. In: ACIAR proceedings, vol 37, pp 101-109

Nkongolo KK, Klimaszewska K (1995) Cytological and molecular relationships between Larix decidua, $L$. leptolepis and Larix $\tilde{A} U^{\circ}$ eurolepis: identification of species-specific chromosoms and synchronization of mitotic cells. Theoretical and Applied Genetics 90(6):827-834

Nychka D, Furrer R, Paige J, Sain S (2015) fields: tools for spatial data. $\mathrm{R}$ package

Pâques LE (1989) A critical review of larch hybridization and its incidence on breeding strategies. Annales des Sciences Forestières 46:141-153

Pâques LE (1992a) First evaluation of genetic parameters in a factorial mating design with hybrid larch (Larix decidua $\tilde{A} U^{\circ}$ Larix kaempferi). In: Weisgerber 
Version définitive du manuscrit publié dans / Final version of the manuscript published in : Tree Genetics \& Genomes, october 2017, https://doi.org/10.1007/s11295-017-1177-1

$\mathrm{H}$ (ed) Results and future trends in larch breeding on the basis of provenance research. IUFRO meeting of the IUFRO working party $\mathrm{S} 2.02-07$, IUFRO, vol 2, pp 136-145

Pâques LE (1992b) Performance of vegetatively propagated Larix decidua, L. kaempferi and L. laricina hybrids. Annales des Sciences Forestières 49:63-74

Pâques LE (2002) Heterosis in interspecific hybrids between European and Japanese larch. In: Pâques LE (ed) Improvement of larch (Larix sp.) for better growth, stem form and wood quality, INRA. Gap (Hautes-Alpes), Auvergne-Limousin, France, pp 155-163

Pâques LE (2004) Roles of European and Japanese larch in the genetic control of growth, architecture and wood quality traits in interspecific hybrids (Larix $\tilde{A} U^{\circ}$ eurolepis Henry). Annals of Forest Science 61(1):25-33, DOI 10.1051/forest: 2003081, URL http://www .edpsciences.org/10. 1051 /forest : 2003081

Pâques LE (2013) Larches (Larix sp.). In: Pâques LE (ed) Forest Tree Breeding in Europe, vol Managing Forest Ecosystem, Springer Science \& Business Media, Dordrecht, Heidelberg, New York, London, pp 13-122

Pâques LE, Charpentier JP (2015) Perspectives for genetic improvement in heartwood size and extractive content in relation to natural durability and aesthetics in interspecific hybrid larch (Larix $\tilde{A} U^{\circ}$ eurolepis). European Journal of Forest Research 134(5):857-868, DOI 10.1007/s10342-015-0895-x, URL http://link.springer.com/10.1007/ s10342-015-0895-x

Perron M (2008) A strategy for the second breeding cycle of Larix $\tilde{A} U^{\circ}$ marschlinsii in Québec, Canada including experiments to guide interspecific tree breeding programme. Silvae Genetica 57(4):282-291

R Core Team (2015) R: a language and environment for statistical computing. URL https : //www . R-project.org/

Regent Instruments Canada Inc (2008) WinDENDRO for tree-ring analysis

Rondeux J (2003) Les mélèzes, un nouveau défi pour la sylviculture des résineux en Wallonie. In: Les cahiers forestiers de Gembloux, Faculté des Sciences Agronomiques, Unité de Gestion et Economie forestières, Gembloux, Belgique, p 15

Shull GH (1948) What is "heterosis" ? Genetics 33(5):439-446, URL http://www.ncbi.nlm.nih. gov/pmc/articles/PMC1209417/
Sorensen D, Gianola D (2007) Likelihood, Bayesian, and MCMC methods in quantitative genetics. Springer Science \& Business Media, New-York

Stuber CW, Cockerham CC (1966) Gene effects and variances in hybrid populations. Genetics 54(6):1279-1286, URL http://www.ncbi.nlm. nih.gov/pmc/articles/PMC1211293/

Sylvestre-Guinot G, Pâques LE, Delatour C (1999) Hybrid larch resistance to Lachnellula willkommi. Annals of Forest Science 56(6):485-492

Wei X, Borralho NM (1998) Use of individual tree mixed models to account for mortality and selective thinning when estimating base population genetic parameters. Forest science 44(2):246-253

Weng Q, He X, Li F, Li M, Yu X, Shi J, Gan S (2014) Hybridizing ability and heterosis between Eucalyptus urophylla and E. tereticornis for growth and wood density over two environments. Silvae Genetica $63(1-2): 15-24$

Wolak ME (2012) nadiv: an $\mathrm{R}$ package to create relatedness matrices for estimating nonâ $\breve{A} \breve{R}$ additive genetic variances in animal models. Methods in Ecology and Evolution 3(5):792-796

Zobel B, Talbert J (1984) Applied forest tree improvement. John Wiley \& Sons, New York 


\section{Appendix 1: Description of the set-up and data}

Table 3: Mating flesign and number of trees per combination in Saint-Appolinaire. EL: European larch, JL: Japanese larch

\begin{tabular}{|c|c|c|c|c|c|c|c|c|c|c|c|c|c|c|c|c|c|c|c|c|c|}
\hline & \multicolumn{9}{|c|}{ Diallel EL } & \multicolumn{9}{|c|}{ Diallel JL } & \multicolumn{2}{|c|}{ Polycrosses } \\
\hline & & 104 & 10 & $\equiv 10$ & 166 & 214 & 221 & 222 & 242 & 284 & 3179 & 3180 & 3183 & 3190 & 3193 & 3194 & 3200 & 3203 & 3217 & $\mathrm{EL}$ & JL \\
\hline \multirow[t]{9}{*}{ Diallel EL } & 104 & & 20 & है 21 & 12 & 11 & 33 & 11 & 5 & 26 & 33 & 29 & 38 & 28 & 29 & 31 & 9 & 18 & 33 & & 16 \\
\hline & 106 & 29 & & 36 & 18 & & 12 & 32 & 1 & 8 & 31 & 29 & 22 & 23 & 29 & 33 & 13 & 30 & 14 & & 24 \\
\hline & 109 & & 13 & ت्ञ & 16 & 2 & 16 & 8 & 4 & 4 & 16 & 8 & 2 & 9 & 9 & 21 & 17 & 13 & 10 & & \\
\hline & 166 & & & $\overrightarrow{\bar{\Xi}}$ & & & & & & & 14 & 11 & 1 & & & & 10 & & & & \\
\hline & 214 & & & $\Sigma$ & & & & & & & 7 & 14 & 5 & & 4 & 4 & 9 & & 11 & 25 & \\
\hline & 221 & 5 & & 0 & 8 & 9 & & 12 & & 16 & 10 & 4 & 6 & 7 & 24 & 17 & 7 & 5 & 6 & & \\
\hline & 222 & & & & 1 & & & & & & 25 & 11 & & 21 & 23 & 9 & 18 & 11 & & & \\
\hline & 242 & & 33 &. & 5 & & 9 & 11 & & & 20 & 18 & 8 & 9 & 29 & 9 & 24 & & 34 & 26 & \\
\hline & 284 & 11 & 12 & $\begin{array}{l}\bar{Z} \\
\underline{n}\end{array}$ & 4 & & & & & & 7 & 21 & 3 & 6 & 14 & 12 & 10 & 18 & 4 & & \\
\hline \multirow[t]{9}{*}{ Diallel JL } & 3179 & 9 & 3 & छ 33 & 19 & 33 & 11 & 38 & 15 & & & 19 & 14 & 20 & 26 & 24 & 13 & 19 & 17 & & 2 \\
\hline & 3180 & 12 & & $\sum 20$ & 15 & 8 & 11 & & 9 & & 26 & & 5 & 9 & 11 & 12 & 9 & 21 & 12 & & 10 \\
\hline & 3183 & 14 & 34 & 17 & 14 & 7 & 10 & 9 & 4 & 14 & 27 & 8 & & 10 & 21 & 14 & 12 & 13 & & & 2 \\
\hline & 3190 & 1 & 13 & $<9$ & 15 & 12 & 12 & 11 & 11 & 12 & 5 & 6 & 3 & & 9 & 2 & 1 & 23 & 8 & & 6 \\
\hline & 3193 & 7 & 8 & $\Xi$ & 16 & 6 & 11 & & 11 & & 4 & 7 & 22 & 6 & & 4 & 24 & 25 & 18 & & 16 \\
\hline & 3194 & & & 㫕 & 8 & & & & 12 & & 16 & 10 & 6 & & 13 & & 1 & 28 & 9 & & 4 \\
\hline & 3200 & & & $\stackrel{0}{=}$ & & & 8 & & & & & 13 & 9 & 4 & 6 & 2 & & & & & 7 \\
\hline & 3203 & 13 & 14 & 당 29 & 8 & 14 & 17 & & 13 & 2 & 13 & 36 & 2 & 7 & 4 & 8 & 3 & & 7 & & \\
\hline & 3217 & 39 & 17 & 忢 18 & 15 & & 49 & & 11 & & 36 & 32 & 13 & 2 & 16 & 24 & 19 & 20 & & & 11 \\
\hline \multirow[t]{6}{*}{ Extra EL } & 78 & & & $\sum$ & & & & & & & & & 8 & & 8 & 8 & & & & & \\
\hline & 108 & & & & & & & & & & 11 & 12 & 22 & 17 & & & & & & & \\
\hline & 129 & & & & & & & & & & 11 & 7 & 30 & 7 & 14 & & & & & & \\
\hline & 147 & & &. & & & & & & & 1 & & & & & & & & & & \\
\hline & 151 & & & 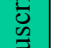 & & & & & & & 14 & 29 & 20 & 4 & 19 & & 4 & & & & \\
\hline & 229 & & & $\overrightarrow{\mathrm{G}}$ & & & & & & & 7 & 9 & 23 & 7 & 4 & & & & & & \\
\hline
\end{tabular}


Version définitive du manuscrit publié dans / Final version of the manuscript published in :

Tre

Table 4: Matể

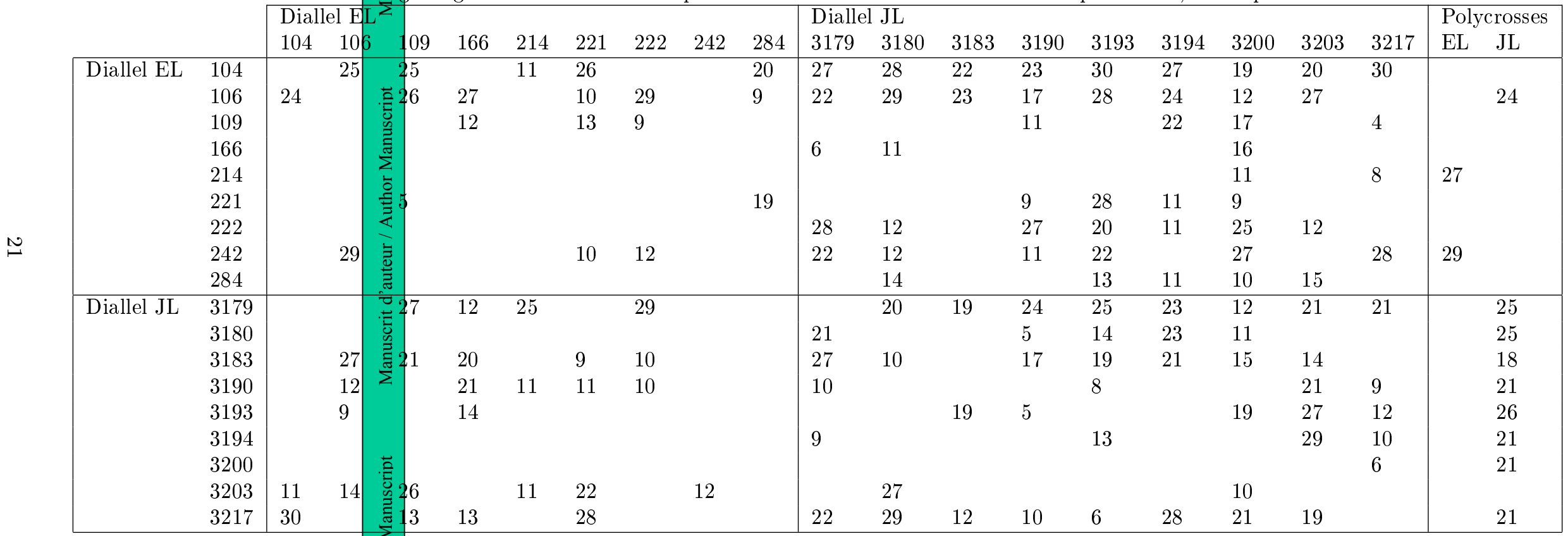




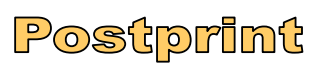

Version définitive du manuscrit publié dans / Final version of the manuscript published in :

Treor

Table 5: Mating 息esign and number of trees per combination in Peyrat-le-Château. EL: European larch, JL: Japanese larch \begin{tabular}{|l|l|}
\hline Diallel EL & Diallel JL
\end{tabular}

\begin{tabular}{|c|c|c|c|c|c|c|c|c|c|c|c|c|c|c|c|c|c|c|c|}
\hline & & $\begin{array}{l}\text { Diallel E } \\
104\end{array}$ & 109 & 166 & 214 & 221 & 222 & 242 & 284 & $\begin{array}{l}\text { Diall } \\
3179\end{array}$ & $\begin{array}{l}\text { JL } \\
3180\end{array}$ & 3183 & 3190 & 3193 & 3194 & 3200 & 3203 & 3217 & $\begin{array}{l}\text { Polycrosses } \\
\text { EL JL }\end{array}$ \\
\hline Diallel EL & 104 & 32 & 30 & & 29 & 31 & & & 26 & 31 & 32 & 32 & 28 & 32 & 34 & 33 & 31 & 26 & \\
\hline & 106 & &. & 28 & & 21 & 25 & & 21 & 29 & 28 & 29 & 31 & 27 & 31 & 25 & 33 & & \\
\hline & 109 & & $\begin{array}{l}5 \\
0 \\
0\end{array}$ & 30 & & 25 & 15 & & & & & & 25 & & 34 & 29 & & & \\
\hline & 166 & & ส్ & & & & & & & & 25 & & & & & 26 & & & \\
\hline & 214 & & $\Sigma$ & & & & & & & & & & & & & 26 & & 21 & 35 \\
\hline & 221 & & 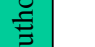 & & & & & & 30 & & & & 3 & 31 & 24 & 23 & & & \\
\hline & 222 & & $\overline{<}$ & & & & & & & & 32 & & 30 & 28 & 24 & 31 & 28 & & \\
\hline & 242 & 31 & $\bar{\Xi}$ & & & 24 & 28 & & & 32 & 32 & & 25 & 32 & & 29 & & 29 & 31 \\
\hline & 284 & & ప్ & & & & & & & & 31 & & & 26 & 27 & 27 & 34 & & \\
\hline Diallel JL & 3179 & & $=31$ & 27 & 33 & & 29 & & & & 28 & 30 & 28 & 25 & 26 & 27 & 27 & 30 & \\
\hline & 3180 & & $\begin{array}{l}\overrightarrow{0} \\
0 \\
g\end{array}$ & & & & & & & & & & 8 & 18 & 21 & 16 & & & \\
\hline & 3183 & & 壱 28 & 32 & & 22 & 27 & & & & 20 & & 33 & 28 & 26 & 26 & 28 & & \\
\hline & 3190 & & & 31 & 29 & 24 & & & & & & & & 19 & & & 26 & 20 & \\
\hline & 3193 & & & 32 & & & & & & & & & 8 & & & 32 & 32 & 25 & \\
\hline & 3194 & & & & & & & & & & & & & 27 & & & 26 & 23 & \\
\hline & 3200 & & & & & & & & & & & & & & & & & & \\
\hline & 3203 & & ర్ల్ 32 & & 26 & 25 & & 28 & & & 28 & & & & & 28 & & & \\
\hline & 3217 & & Е 34 & 30 & & 31 & & & & & 30 & 25 & 7 & & 3 & 32 & 31 & & \\
\hline
\end{tabular}


Version définitive du manuscrit publié dans / Final version of the manuscript published in :

Tree Genetics \& Genomes, october 2017, https://doi.org/10.1007/s11295-017-1177-1

Table 6: Description of the environment of the 3 sites

\begin{tabular}{llllllll}
\hline Site & Coordinates & $\begin{array}{l}\text { Altitude } \\
(\mathrm{m})\end{array}$ & $\begin{array}{l}\text { Slope } \\
(\%)\end{array}$ & $\begin{array}{l}\text { Mean Temp } \\
\left({ }^{\circ} \mathrm{C}\right)\end{array}$ & $\begin{array}{l}\text { Rain } \\
(\mathrm{mm})\end{array}$ & $\begin{array}{l}\text { Previous } \\
\text { crop }\end{array}$ & $\begin{array}{l}\text { Spacing } \\
\text { of plantation }\end{array}$ \\
\hline SA (Saint-Appolinaire) & $45^{\circ} 58^{\prime} \mathrm{N} 4^{\circ} 26^{\prime} \mathrm{E}$ & 784 & 22.3 & 14 & 649 & Forest & $3 \mathrm{~m} \times 3 \mathrm{~m}$ \\
SS (Saint-Saud) & $45^{\circ} 31^{\prime} \mathrm{N} 0^{\circ} 48^{\prime} \mathrm{E}$ & 307 & 4.7 & 16.3 & 620 & Pasture & $\begin{array}{l}4 \mathrm{~m} \times 2.5 \mathrm{~m} \\
\text { PC (Peyrat-le-Château) }\end{array}$ \\
$45^{\circ} 49^{\prime} \mathrm{N} 1^{\circ} 44^{\prime} \mathrm{E}$ & 461 & 5.2 & 15.4 & 651 & Forest & $3 \mathrm{~m} \times 2.5 \mathrm{~m}$ \\
\hline
\end{tabular}

1 from $04 / 01$ to $10 / 31$

Table 7: Age of the trees (years after plantation) during the increment cores samplings, in Saint Appolinaire (SA), Saint-Saud (SS) and Peyrat-le-Château (PC)

\begin{tabular}{llll}
\hline site & last year & age & sample size \\
\hline SA & 2015 & 19 & 33 \\
& 2013 & 17 & 2081 \\
SS & 2011 & 15 & 1241 \\
& 2009 & 13 & 693 \\
& 2003 & 7 & 915 \\
PC & 2015 & 12 & 200 \\
& 2014 & 11 & 1094 \\
\hline
\end{tabular}

Table 8: Traits involved in multi-trait analysis, with indication of age (years after plantation); for each site: Saint Appolinaire (SA), Saint-Saud (SS) and Peyrat-le-Château (PC). Traits at a young stage, indicated '(y)', were introduced in SS in order to account for thinning censure

\begin{tabular}{|c|c|c|c|c|}
\hline \multirow[t]{2}{*}{ Trait } & & \multicolumn{3}{|c|}{ Site } \\
\hline & & $\mathrm{SA}$ & SS & $\mathrm{PC}$ \\
\hline \multirow[t]{2}{*}{ Breast height circumference } & $\mathrm{BHC}$ & 14 & 13 & 11 \\
\hline & $\mathrm{BHC}(\mathrm{y})$ & & 7 & \\
\hline \multirow[t]{2}{*}{ Total height } & HT & 14 & 13 & 11 \\
\hline & HT (y) & & 7 & \\
\hline \multirow[t]{2}{*}{ Wood density } & DEN & 14 & 13 & 11 \\
\hline & DEN (y) & & 7 & \\
\hline Heartwood proportion & HWP & 17 & 13 to 15 & 11 \\
\hline \multirow[t]{2}{*}{ Stem flexuosity } & FLX & 14 & 13 & 11 \\
\hline & FLX (y) & & 7 & \\
\hline Bud flush & BUD & 2 & 2 & 3 \\
\hline
\end{tabular}


Version définitive du manuscrit publié dans / Final version of the manuscript published in :

Tree Genetics \& Genomes, october 2017, https://doi.org/10.1007/s11295-017-1177-1
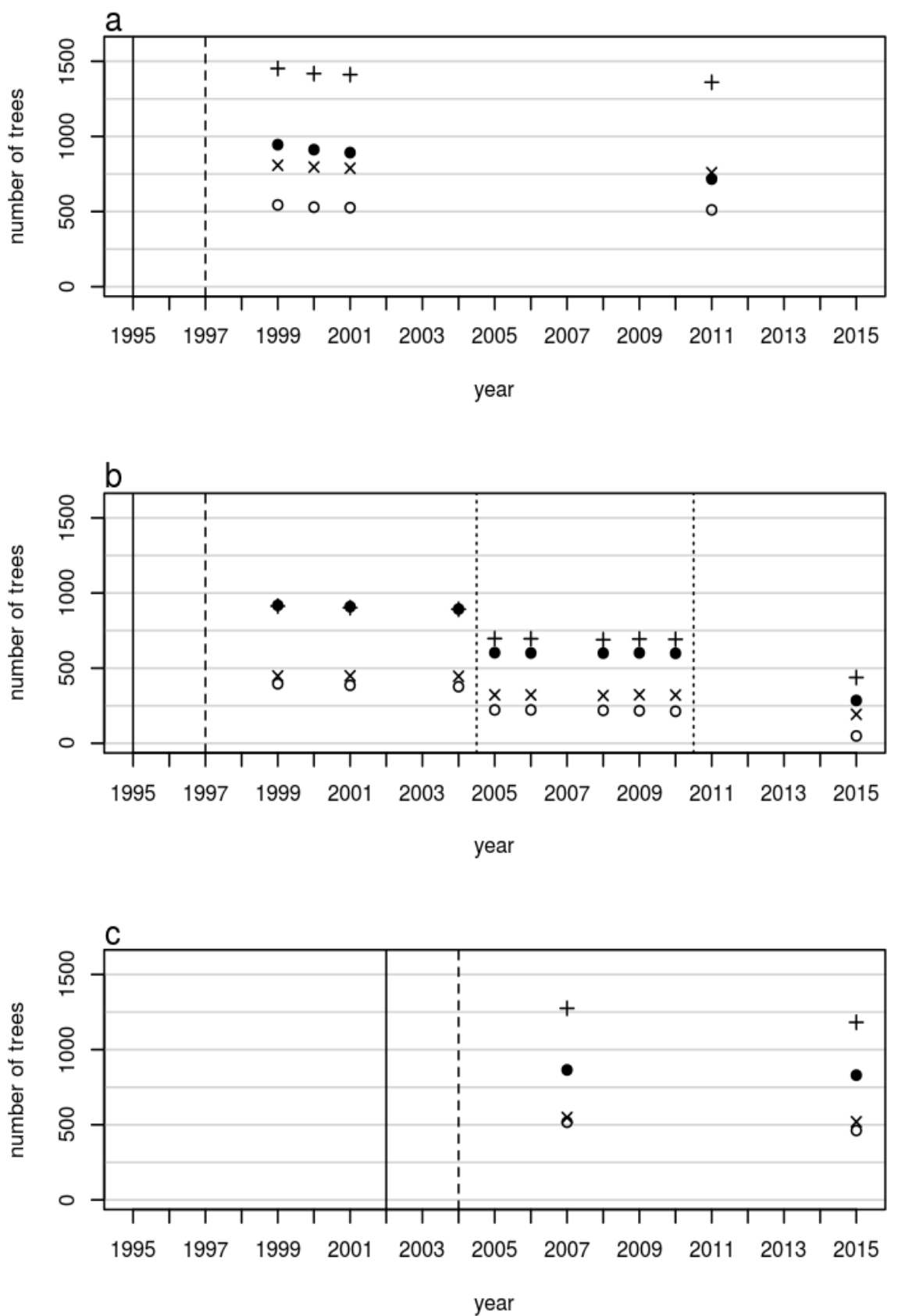

Figure 4: Evolution of the size of the set-up, in each site (a: Saint-Appolinaire, b: Saint-Saud, c: Peyrat-leChâteau) and for each taxon (black dot: Japanese larch, white dot: European larch, +-shaped dot: EL $\times$ JL hybrid, $\times$-shaped dot: JL $\times$ EL hybrid). Vertical bars indicate the main operations. Plain bar: sowing (in SA and SS) or grafting (in PC), dashed line: plantation, dotted line: thinnings (in Saint-Saud only) 
Version définitive du manuscrit publié dans / Final version of the manuscript published in :

Tree Genetics \& Genomes, october 2017, https://doi.org/10.1007/s11295-017-1177-1

\section{Appendix 2: Extra results}
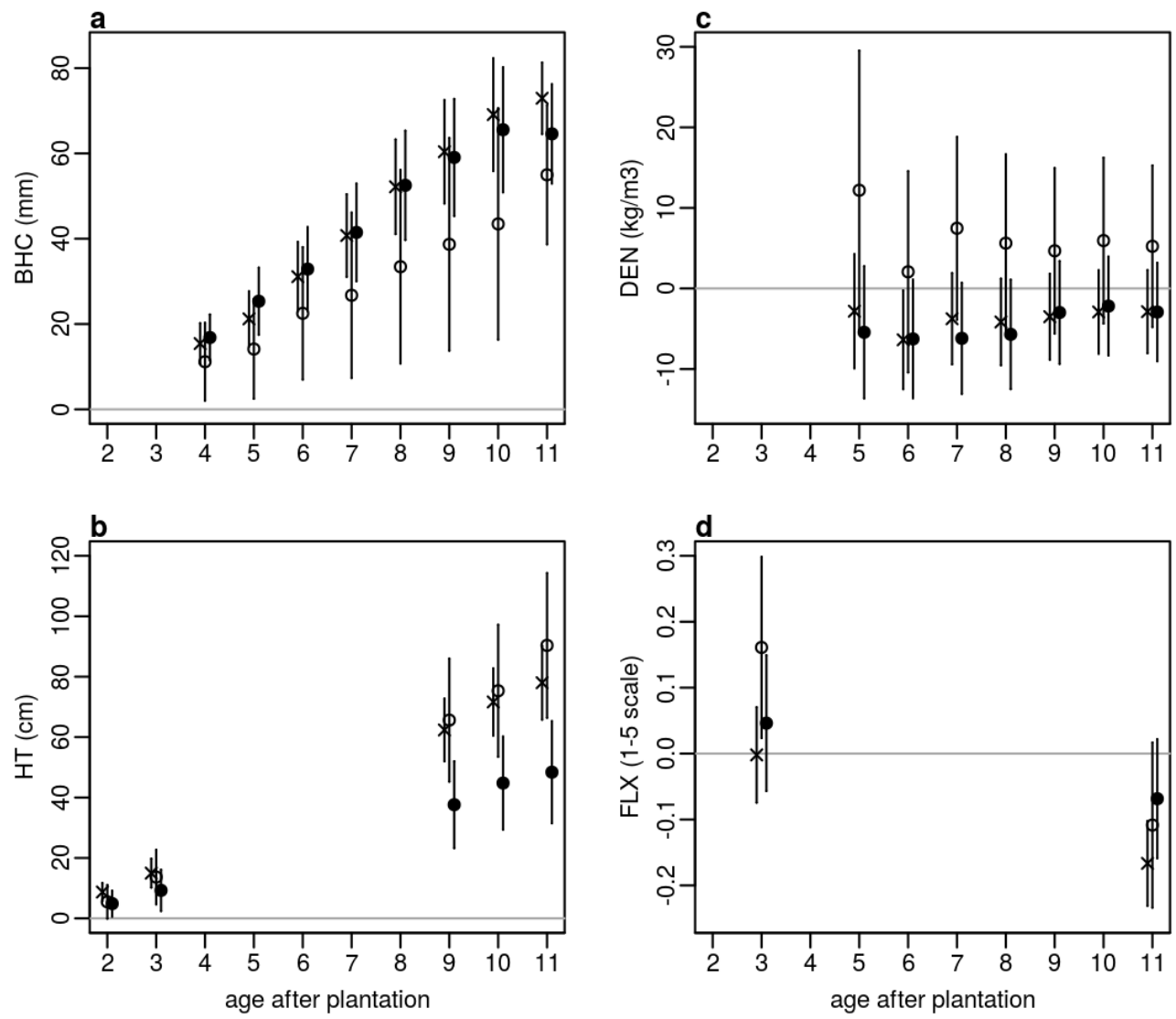

Figure 5: Hybrid rootstock effect in Peyrat-le-Château, defined, for each scion taxon, as the contrast between trees whose rootstock was HL (hybrid larch) and trees whose rootstock was JL (Japanese larch), for breast height circumference (a), height (b), wood density (c) and stem flexuosity (d). White dot: European larch scions; black dot: JL scions; $\times$-shaped dot: HL scions. All vertical bars: $95 \%$ confidence intervals under normal distribution assumption 
Version définitive du manuscrit publié dans / Final version of the manuscript published in :

Tree Genetics \& Genomes, october 2017, https://doi.org/10.1007/s11295-017-1177-1

Table 9: Means (m) and coefficients of variation (CV) from model M2, for European larch (EL), Japanese larch (JL) and their hybrid (HL), in Saint-Appolinaire (SA), Saint-Saud (SS) and Peyrat-le-Château (PC), for the 6 traits under study; and spatial variance proportions (SVP) and spatial autoregressive parameters $(\rho)$ from model M1. The asterisk $(*)$ indicates that $\rho$ has been arbitrarily fixed to 0.99. Breast-height circumference (BHC) was expressed in mm, total height (HT) was expressed in $\mathrm{cm}$, wood density (DEN) was expressed in kg.m ${ }^{-} 3$, heartwood proportion (HWP) was expressed in \%, stem flexuosity (FLX) was a 1 to 5 mark, terminal bud flush was a 0 to 6 mark; the CVs and SVPs were expressed in \%

\begin{tabular}{|c|c|c|c|c|c|c|c|c|c|}
\hline \multirow{3}{*}{ site } & \multirow{3}{*}{ trait } & \multicolumn{6}{|c|}{ Model M2 } & \multicolumn{2}{|c|}{ Model M1 } \\
\hline & & \multicolumn{2}{|l|}{ EL } & \multicolumn{2}{|l|}{$\mathrm{JL}$} & \multicolumn{2}{|l|}{ HL } & \multirow[b]{2}{*}{$\rho$} & \multirow[b]{2}{*}{ SVP } \\
\hline & & $\mathrm{m}$ & $\mathrm{CV}$ & $\mathrm{m}$ & $\mathrm{CV}$ & $\mathrm{m}$ & $\mathrm{CV}$ & & \\
\hline \multirow[t]{6}{*}{$\mathrm{SA}$} & $\mathrm{BHC}$ & 465.21 & 21.9 & 406.47 & 18.6 & 552.09 & 16.4 & 0.99 & 44.6 \\
\hline & $\mathrm{HT}$ & 1038.26 & 12.7 & 897.68 & 11.3 & 1154.2 & 11.2 & 0.99 & 68.3 \\
\hline & DEN & 475.56 & 8.4 & 398.48 & 9.2 & 428.06 & 9.8 & 0.99 & 7.1 \\
\hline & HWP & 56.56 & 22.4 & 55.61 & 23.3 & 58.46 & 20.6 & 0.99 & 14.6 \\
\hline & FLX & 3.23 & 30 & 3.66 & 26 & 3.39 & 34.9 & 0.99 & 5.5 \\
\hline & BUD & 2.42 & 39.1 & 2.39 & 39.4 & 2.35 & 48.4 & 0.99 & 7.3 \\
\hline \multirow[t]{6}{*}{$\mathrm{SS}$} & $\mathrm{BHC}$ & 553.26 & 22.3 & 672.15 & 11.8 & 763.88 & 13.8 & 0.96 & 22 \\
\hline & HT & 1476.3 & 10.5 & 1503.84 & 6.3 & 1670.89 & 8.1 & 0.96 & 48 \\
\hline & DEN & 425.86 & 9 & 369.55 & 9.6 & 393.09 & 10.1 & 0.94 & 6.8 \\
\hline & HWP & 59.87 & 18 & 62.84 & 15 & 63.35 & 17.9 & 0.96 & 8.9 \\
\hline & FLX & 3.23 & 29.2 & 3.6 & 24.8 & 3.22 & 35.4 & 0.83 & 2.2 \\
\hline & BUD & 2.75 & 35.8 & 2.38 & 35.3 & 2.02 & 58.1 & 0.98 & 5.7 \\
\hline \multirow[t]{6}{*}{$\mathrm{P}$} & $\mathrm{BHC}$ & 335.65 & 24.9 & 481 & 15.9 & 452.54 & 21.5 & 0.95 & 23.8 \\
\hline & HT & 1030.21 & 14.2 & 1196.4 & 7.4 & 1255.6 & 11.7 & 0.92 & 52.5 \\
\hline & DEN & 401.81 & 7.2 & 386.59 & 7.4 & 402.63 & 10.2 & 0.99 & 7.2 \\
\hline & HWP & 36.03 & 34.9 & 44.91 & 20.7 & 43.54 & 29.3 & 0.87 & 11.6 \\
\hline & FLX & 3.91 & 20.1 & 4.12 & 20.4 & 3.64 & 33.5 & $0.99^{*}$ & 87.5 \\
\hline & BUD & 3.61 & 18.6 & 3.87 & 17 & 3.63 & 24 & $0.99^{*}$ & 46.4 \\
\hline
\end{tabular}


Version définitive du manuscrit publié dans / Final version of the manuscript published in : Tree Genetics \& Genomes, october 2017, ～https://doi.org/10.1007/s11295-017-1177-1
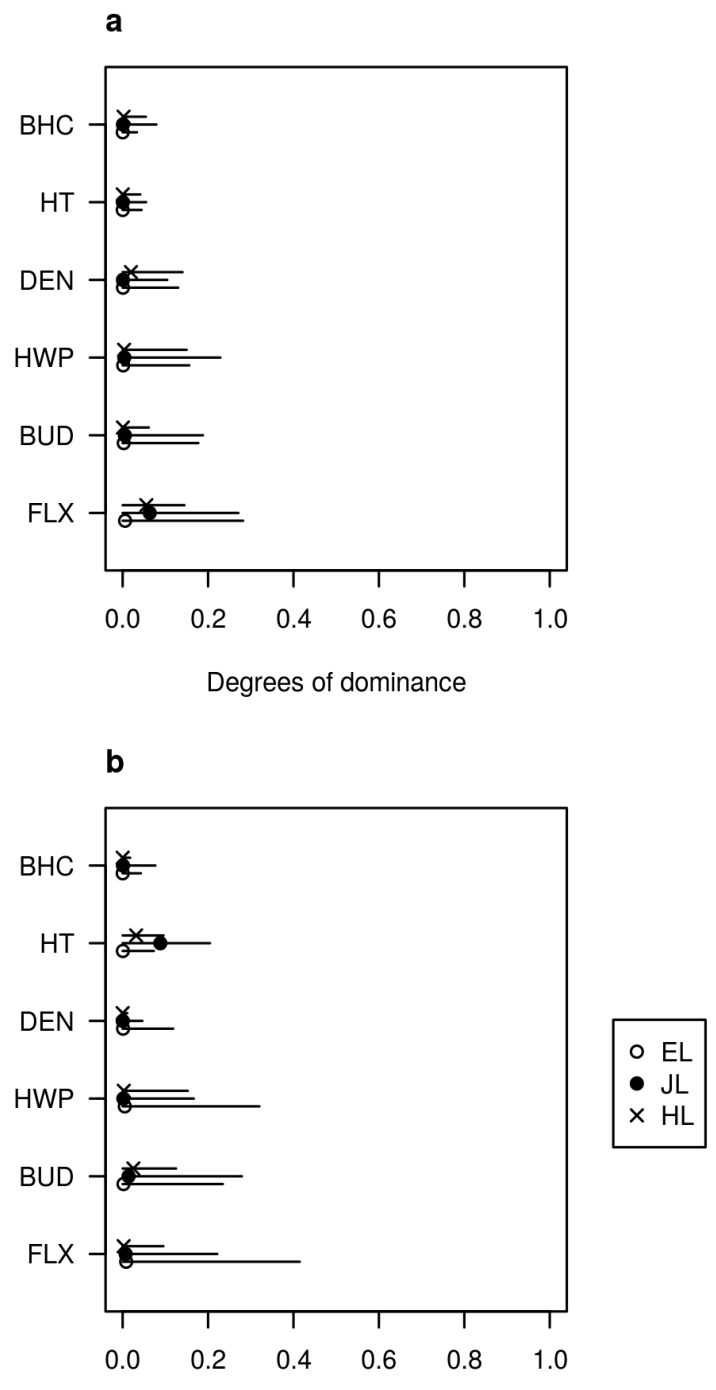

Degrees of dominance

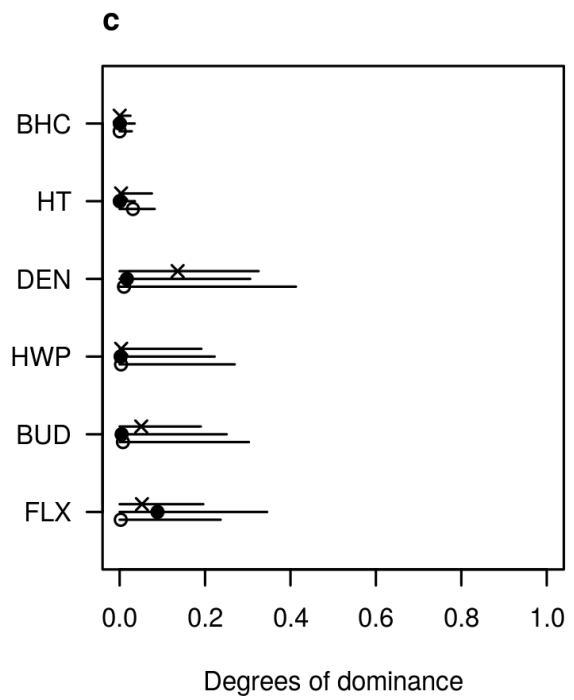

Figure 6: Degrees of dominance, in Saint-Appolinaire (a), Saint-Saud (b), and Peyrat-le-Château (c). White dot: European larch; black dot: Japanese larch; $\times$-shaped dot: hybrid larch. Horizontal lines: $95 \%$ CIs 
Version définitive du manuscrit publié dans / Final version of the manuscript published in : Tree Genetics \& Genomes, october 2017, ｈttps://doi.org/10.1007/s11295-017-1177-1
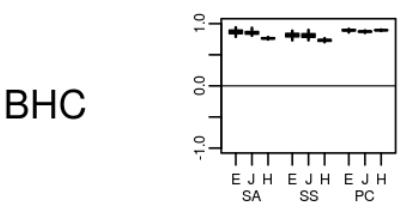

HT

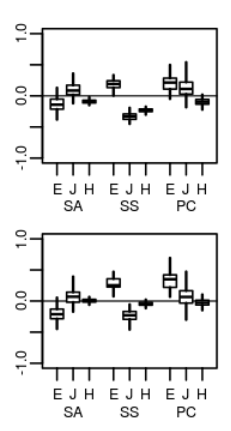

DEN
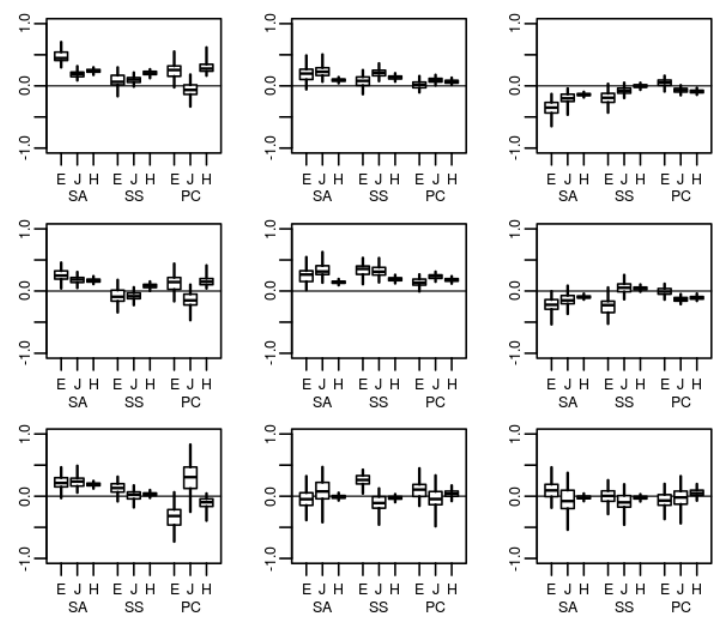

HWP

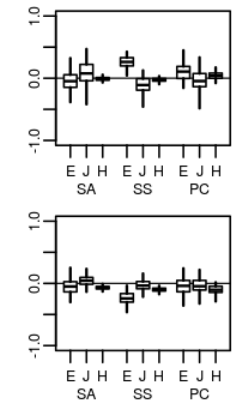

FLX
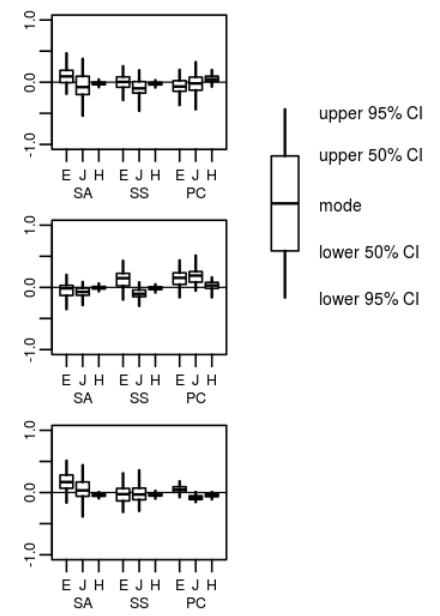

BUD

Figure 7: Residual correlations between the traits: breast-height circumference (BHC), total height (HT), wood density (DEN), heartwood proportion (HWP), stem flexuosity (FLX), bud flush (BUD); for each taxon ('E': European larch, 'J': Japanese larch, 'H': hybrid larch); in each site: Saint-Appolinaire (SA), Saint-Saud (SS) and Peyrat-le-Château (PC). Whiskers: 95\% CIs; box: 50\% CIs; middle-line: mode (i.e. maximum a posteriori) 
Appendix 3: Perfor
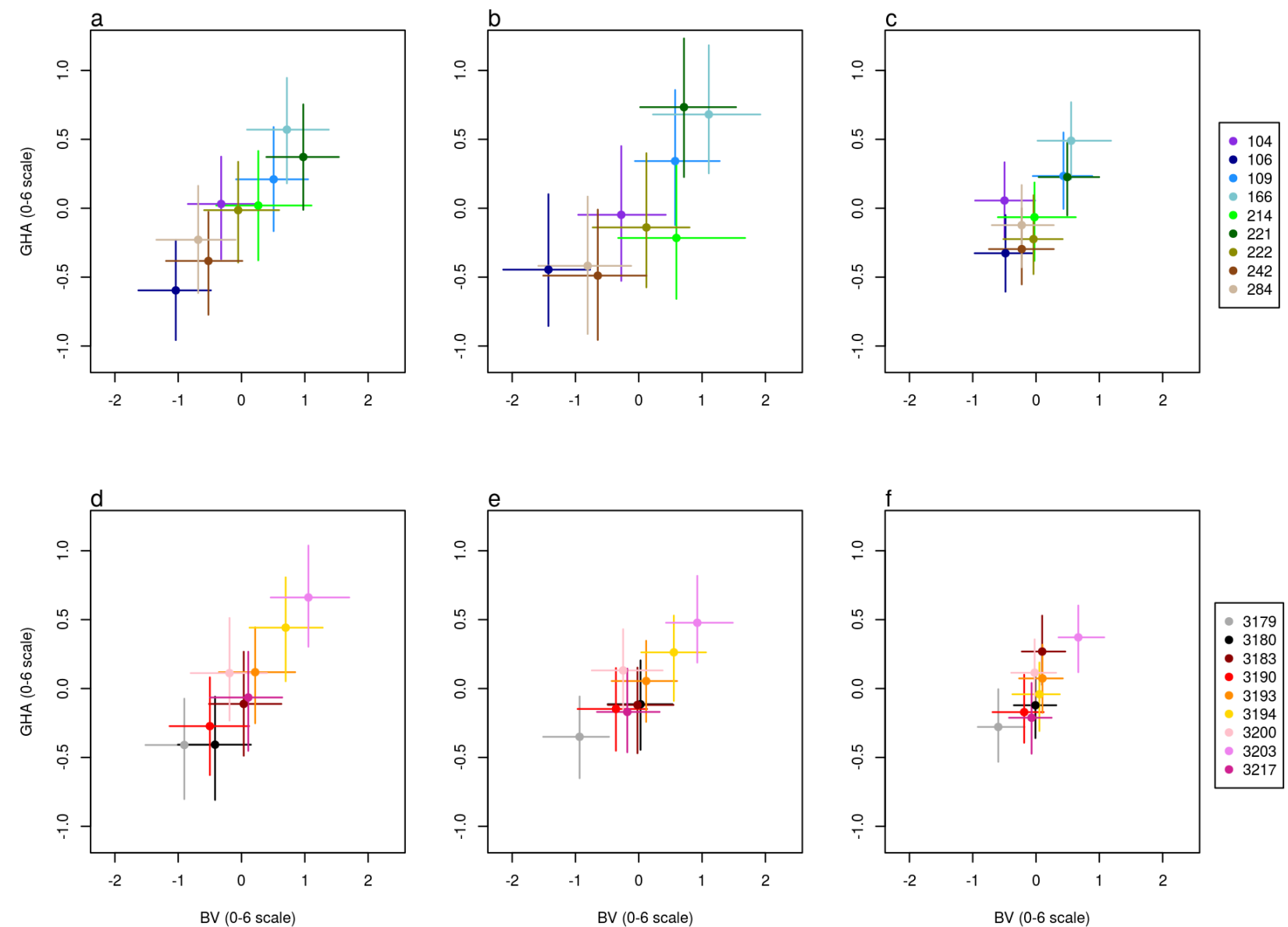

Figure 8: Performances of the 9 玉turopean larch parents (a-c) and the 9 Japanese larch parents (d-f) for bud flush, in pure species breeding (BV: breeding value) and in hybridization (GH: $(c, f)$. For each species, the labets of the trees associated with each dot are provided on the side. The horizontal and vertical grey bars are $95 \%$ CIs. Higher marks mean earlier bud flushes 

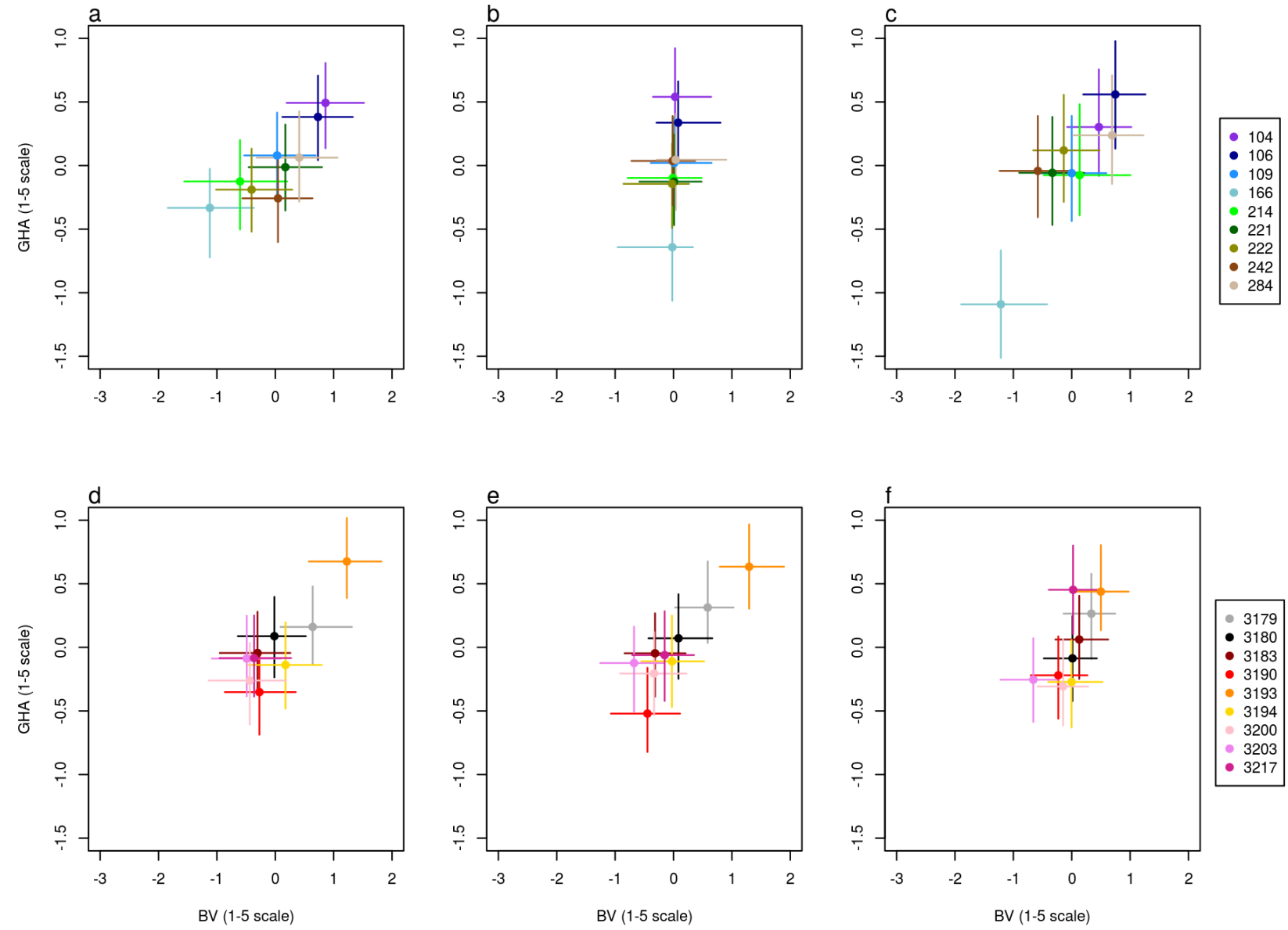

Figure 9: Performances of the 9 European larch parents (a-c) and the 9 Japanese larch parents (d-f) for stem flexuosity, in pure species breeding (BV: breeding value) and in hybridizafion (GHA: general hybridization ability), in each of the 3 sites: Saint-Appolinaire (a,d), Saint-Saud (b, e) and Peyrat-leChâteau (c, f). For each species ${ }^{\sigma}$ the labels of the trees associated with each dot are provided on the side. The horizontal and vertical grey bars are $95 \%$ CIs. Higher marks mean earlier 曹ud flushes 


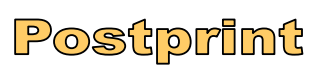

Version définitive du manuscrit publié dans / Final version of the manuscript published in :

Ters
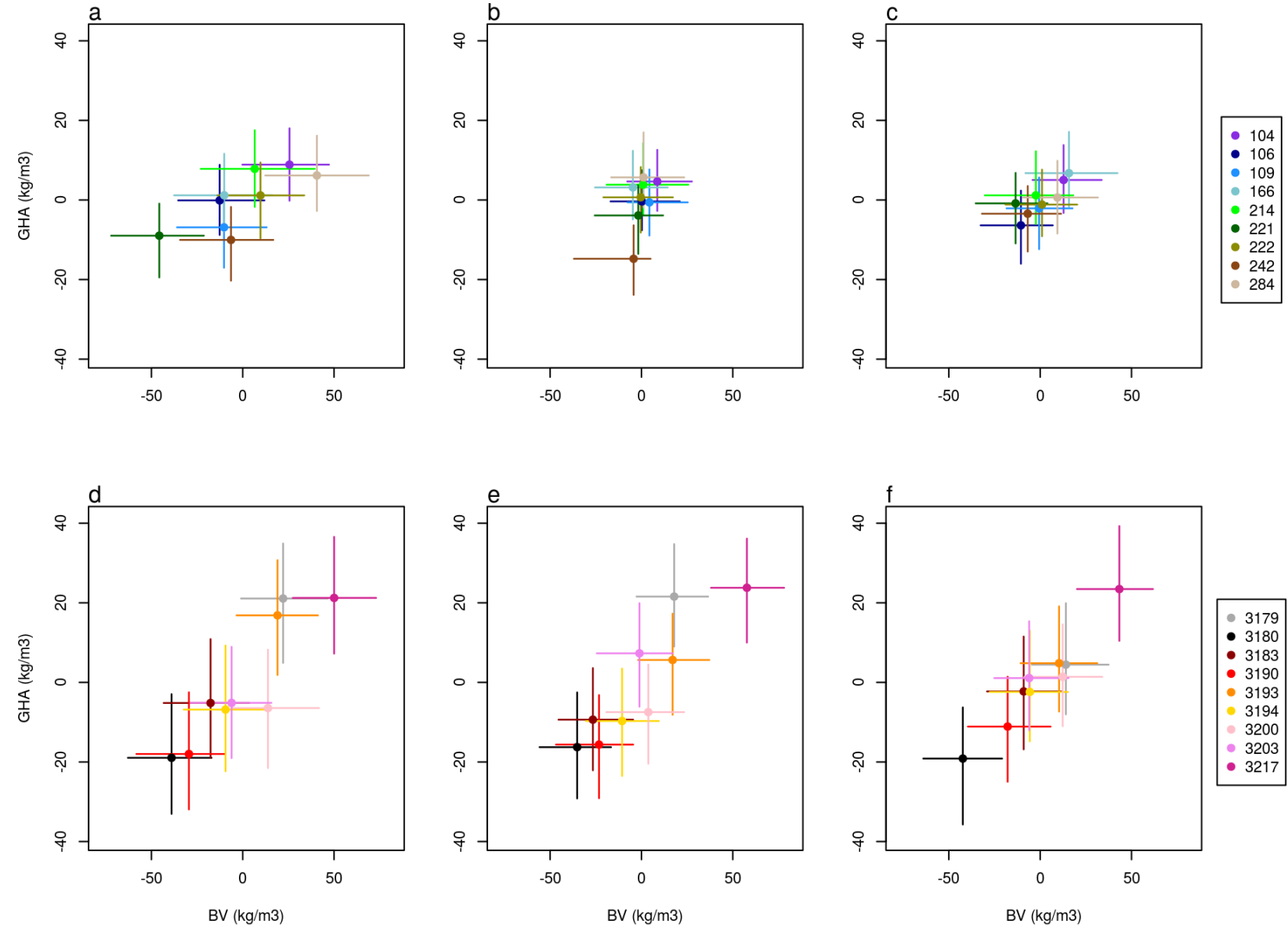

Figure 10: Performances of the 9 European larch parents (a-c) and the 9 Japanese larch parents (d-f) for wood density, in pure species breeding (BV: breeding value) and in hybridization (CH: general hybridization ability), in each of the 3 sites: Saint-Appolinaire (a, d), Saint-Saud (b, e) and Peyrat-le-Château $(c, f)$. For each species, the lapets of the trees associated with each dot are provided on the side. The horizontal and vertical grey bars are $95 \%$ CIs. Higher marks mean earlier bud flushes 

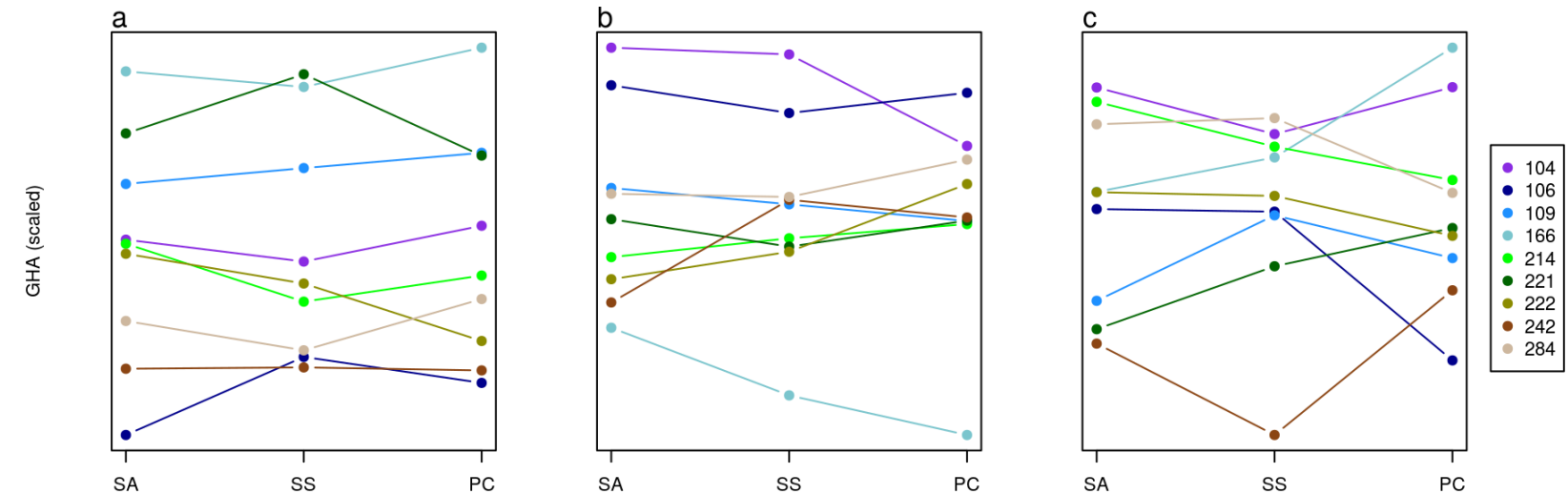

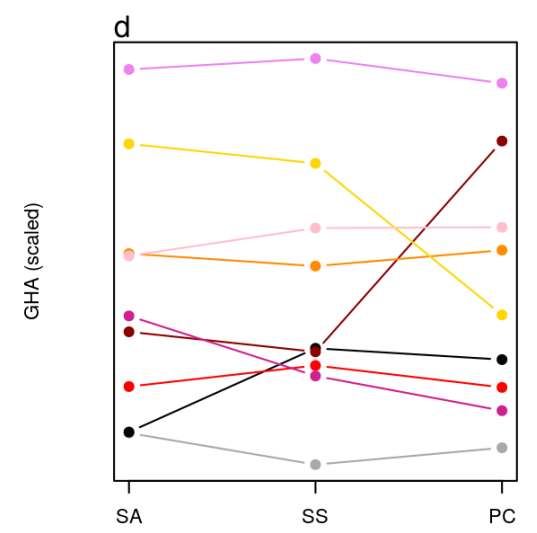

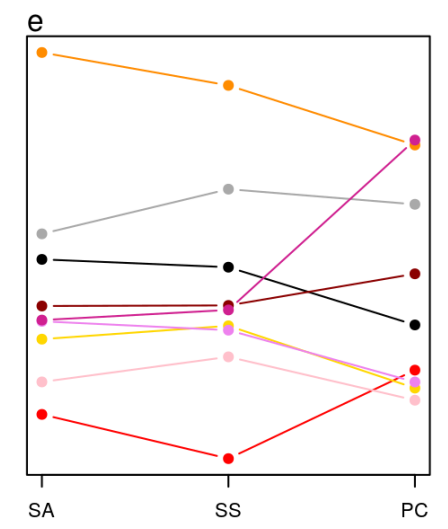

site

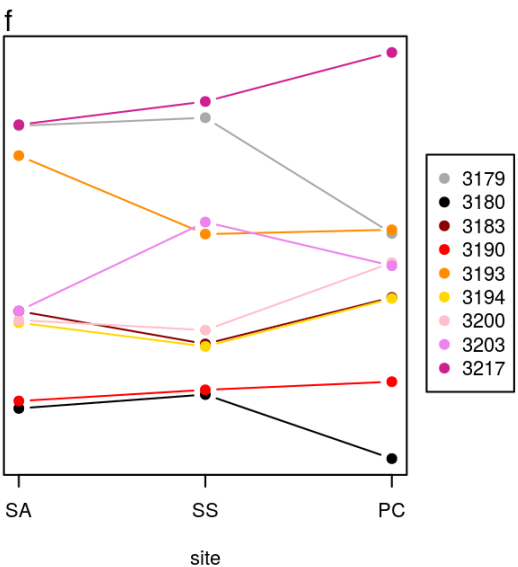

Figure 11: Changes in hybrid la Japanese larch GHA (d-f), for blüّd flush (a, d), stem flexuosity (b, e) and wood density (c, f). All traits were scaled. Test sites were SA: Saint-Appolinaire, SS: Saint-Saud and PC: Peyrat-le्e-Château 
Version définitive du manuscrit publié dans / Final version of the manuscript published in :

Tree Genetics \& Genomes, october 2017, https://doi.org/10.1007/s11295-017-1177-1

\section{Appendix 4: Comparison between the heritabilities estimated in this study and the heritabilities of the literature reviewed by Pâques (2013)}

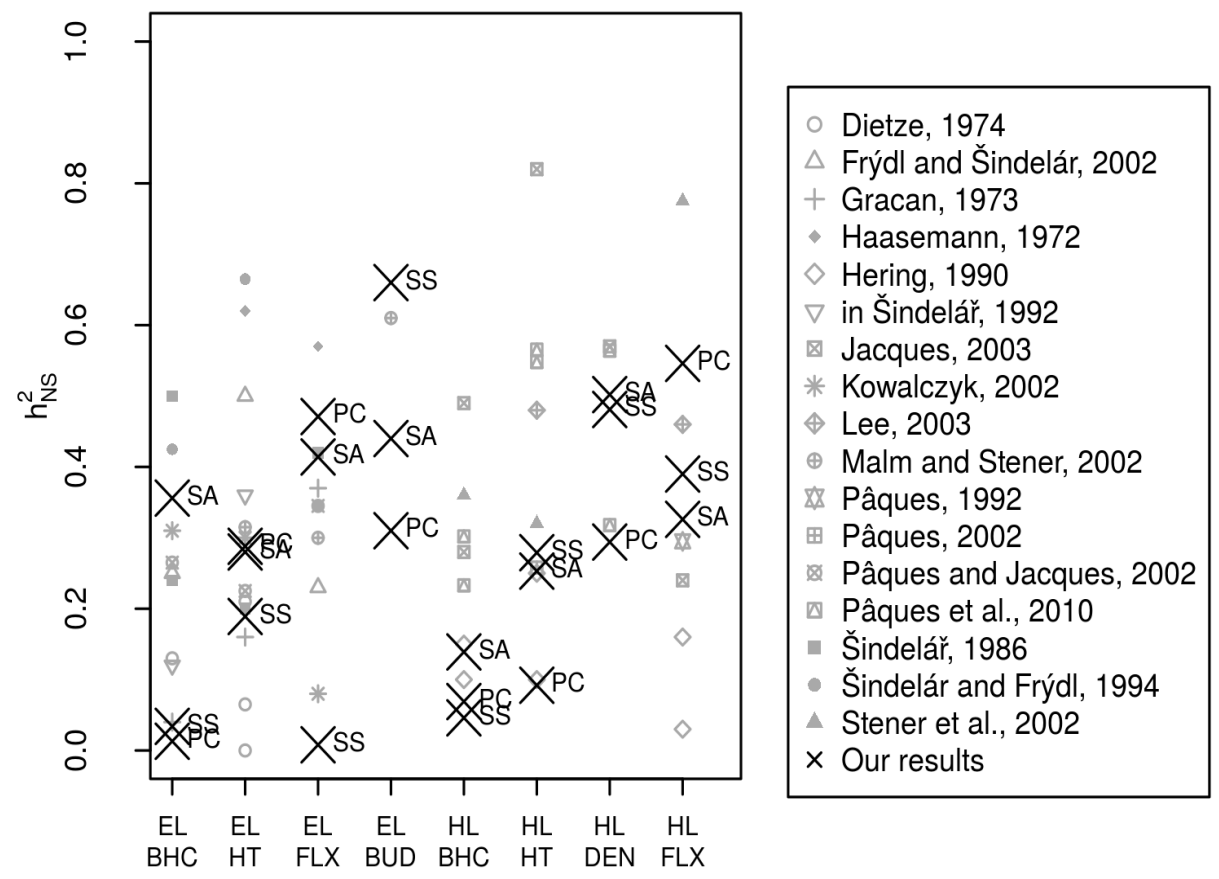

Figure 12: Heritabilities from Fig. 2 ( $\times$-shaped black dots), plotted together with heritabilities from literature (all other grey dots) reviewed in Pâques (2013); for European larch (EL) and Japanese larch (JL); and for the traits breast-height circumference (BHC), total height (HT), wood density (DEN), stem flexuosity (FLX), bud flush (BUD) 